\title{
Le discours comme pouvoir : Yan'an et la révolution chinoise
}

David E. Apter

\section{(2) OpenEdition \\ 1 Journals}

Édition électronique

URL : http://journals.openedition.org/conflits/179

DOI : $10.4000 /$ conflits. 179

ISSN : 1777-5345

Éditeur :

CCLS - Centre d'études sur les conflits lilberté et sécurité, L'Harmattan

Édition imprimée

Date de publication : 15 mai 1994

ISSN : 1157-996X

Référence électronique

David E. Apter, «Le discours comme pouvoir : Yan'an et la révolution chinoise », Cultures \& Conflits [En ligne], 13-14 | printemps-été 1994, mis en ligne le 14 mars 2006, consulté le 30 mars 2021. URL:

http://journals.openedition.org/conflits/179; DOI : https://doi.org/10.4000/conflits.179

Ce document a été généré automatiquement le 30 mars 2021.

Creative Commons License 


\title{
Le discours comme pouvoir : Yan'an et la révolution chinoise
}

\author{
David E. Apter
}

1 Entendant monter le son des sanglots, il se leva et frôla le rideau, pensant : "Karl Marx a écrit Le Capital alors que ses enfants pleuraient autour de lui. Il a du être un grand homme". Lu Xun, "Une famille heureuse"

Yan'an face à Tiananmen

3 Les dernières illusions concernant la permanence de la révolution chinoise ont volé en éclats lors des événements de juin 1989 sur la place Tiananmen ${ }^{1}$. Mais la réalité de cette révolution avait disparu bien avant. Peut-être que quelque part, il subsistait encore pour certains un petit fragment du mythe de Yan'an: mythe qui officiellement du moins, continuait à représenter cet instant de "pureté morale" de la Révolution, son apothéose. Seulement, lorsque les vieux "Yan'anites", Deng Xiaoping, Li Xiannian, Chen Yun, Yang Shangkun, et bien d'autres, décidèrent de mettre fin aux manifestations et de stopper cette éphémère ouverture vers la démocratie, les derniers faux semblants de moralité révolutionnaire s'évanouirent en même temps. En effet le symbolisme ressortant de la mise en parallèle entre Yan'an et Tiananmen était flagrant. La légitimité $\mathrm{du}$ mythe de la dernière révolution chinoise y fut défiée par ses "descendants" supposés, qui, sur la place Tiananmen, ont préféré abandonner ce passé révolutionnaire, et retrouver au delà le mouvement antérieur du 4 mai 1919 avec ses deux principes jumeaux: science et démocratie. Retrouvaille qui, aux yeux des autorités, n'a fait qu'aggraver l'erreur des étudiants de Tiananmen. En effet, pour les dirigeants, Yan'an restait le centre moral d'une des plus grandes révolutions du monde. Tout le monde comprit cependant peu après que Tiananmen marquait la fin de cette révolution là, et laissait présager un nouveau commencement.

4 Yan'an et Tiananmen: deux cultures politiques différentes Yan'an, à son époque, rayonna vers les bases révolutionnaires et de là, à travers toute la Chine, et ce, malgré le contexte de guerre et de révolution allant de 1936 à 1947. Ce fut le moment de transition entre l'échec et le succès à la fois pour Mao Zédong en personne à travers son ascension au sein du $\mathrm{PCC}^{2}$ et pour le Parti lui-même. La transition elle-même ne fut 
pas, comme nous essaierons de le montrer, due seulement à la supériorité tactique, ou à la discipline d'une partie de la huitième Armée de terre, mais s'effectua aussi à travers un discours politique qui s'est auto-constitué et auto-validé. Tiananmen donna le coup de grâce à ce qui était devenu le "mythe" de Yan'an. Seulement Tiananmen ne dura qu'un peu plus de six semaines. Certes, durant ce bref moment, le rayonnement se propagea de la place de Tiananmen vers les centres établis dans les campus universitaires et à travers toute la Chine - les étudiants rassemblés sur la place, reçurent un large soutien de la part d'étudiants et d'intellectuels et de nombreuses autres personnes - mais Tiananmen ne développa ou n'institua jamais de discours propre. Il lui manqua à la fois un langage approprié à la démocratie et un programme. Ses leaders, qui savaient beaucoup mieux ce contre quoi ils luttaient que ce pour quoi ils luttaient, ne proposèrent ni réformes constitutionnelles ni solutions institutionnelles. Et c'est là, l'une des leçons que l'on peut tirer de ces événements : à savoir combien il sera difficile pour demain de trouver des solutions politiques appropriées au cas chinois. Ce sera beaucoup plus complexe que de simplement agiter les bannières de la démocratie et de la science, et de suivre les prescriptions, les slogans de "promoteurs" de la démocratie, qu'ils soient universitaires ou politiques. En effet, étant donné la complexité des conditions économiques et sociales en Chine, l'établissement de cadres constitutionnels et de configurations institutionnelles, pour être efficace et réalisable, devra absolument inhiber les tendances à des solutions standardisées.

5 Malgré les différences existant entre Yan'an et Tiananmen, en termes de durée, d'échelle, de portée et de significations, Tiananmen fut un moment saillant autour duquel se constitua un avant et un après. Aucune des ouvertures précédentes, même celle "du mur de la démocratie" n'eut cet impact car elles furent toutes étouffées plus ou moins brutalement et sans réaction. Tiananmen marqua à cet égard la rupture fondamentale avec Yan'an, en pouvant opposer un haut degré de sens moral démocratique au haut degré de sens moral socialiste, chose à laquelle non seulement les autorités furent vivement sensibles mais qu'elles masquèrent du mieux qu'elles purent. Seulement, plus elles s'y essayèrent, plus elles révélèrent au contraire la distance morale parcourue depuis l'apogée révolutionnaire de Yan'an. Ainsi, au delà de l'apparence des événements d'aujourd'hui, il ne s'agit donc pas simplement d'une lente transition d'un type fondamental de système politique à un autre, mais aussi d'une transformation dans le discours moral au sein d'une problématique culturelle donnée (à l'intérieur de laquelle ceux qui agissent, interprètent le sens de leurs actes). En ce sens, comparer Yan'an et Tiananmen met l'accent sur le fait que la situation politique chinoise actuelle doit être analysée comme un choc entre des cultures politiques différentes plutôt que comme une évolution du pré-démocratique vers le démocratique ${ }^{3}$.

En politique, chacun définit et soutient un centre moral différent. Centre qui catalyse un désir politique différent, et est confronté à des réalités différentes. A ce titre, tant que les vieux Yan'anites resteront au pouvoir, Yan'an et Tiananmen constitueront des pôles opposés, situation que les défenseurs d'une réforme politique à Tiannamen avaient précisément espéré éviter. En effet si, plus les pôles s'opposent, et plus l'interconnexion entre le symbolique et l'évaluatif est significative pour l'analyse critique, il est en revanche plus difficile pour les acteurs sociaux de conduire des réformes par la voie de la médiation. Les autorités ont vu en effet dans la réforme une perte de contrôle, un chaos, c'est à dire ce pôle négatif originel que la révolution avait 
voulu transcendé, et qui, pour elles, menaçait encore une fois le futur de la Chine. Elles ont donc voulu réprimer au plus vite mais, en essayant dans la lutte de vaincre de cette manière, l'Etat a réduit ses citoyens à la position de sujets. Il n'en a fait que ressortir plus clairement encore aujourd'hui qu'à l'époque que les événements de la place Tiananmen définissent un projet de libération, un moment moral, permettant cette fois de convertir les sujets en citoyens avec des droits et de faire de l'Etat le sujet du peuple, relevant de la responsabilité du peuple.

7 La comparaison de ces deux moments fait donc sens. Malgré leur côté éphémère, les événements de la place Tiananmen s'opposent à l'histoire longue de Yan'an, qui avait pris, à force, l'allure d'une anti-histoire. Il ne fait aucun doute qu'il faudra du temps pour que les questions soulevées à Tiananmen deviennent politiquement manifestes, et s'élaborent en discours politique. Mais si l'on relie Yan'an et Tiananmen, l'on obtient une trajectoire nette grâce à laquelle il est possible d'avoir une perspective sur le socialisme chinois ou du moins ce qu'il en reste. C'est pourquoi, je veux discuter dans cet article cette trajectoire en me référant à Yan'an comme point d'ancrage du processus révolutionnaire et à Tiananmen comme point de décentrage de ce même processus.

8 Yan'an et Tiananmen comme "simulacres" Si l'on n'intègre pas en effet dans l'analyse le pouvoir et la signification de Yan'an, il n'est pas possible de véritablement comprendre l'aspect pathétique de Tiananmen C'est pourquoi nous nous concentrerons sur Yan'an et sur la façon dont il a créé son propre discours comme base du pouvoir. Nous discuterons comment un processus de lien exégétique (" exegetical bonding ») ${ }^{4}$ basé sur une "oralité" et une écriture, sur une narration et sur un texte, dans lequel les mots sont devenus les instruments d'un triomphe à la fois de l'individuel et du collectif, s'est forgé. A travers ce processus, les individus se transcendèrent et se fondirent dans la collectivité. Il sera nécessaire de voir comment aux confins de Yan'an, le temps s'est converti en espace, l'histoire s'est stoppée en un moment révolutionnaire disjonctif. Yan'an devint alors le simulacre d'une société en attente de naître, et cet "effet de simulacre" fut la conséquence d'une aufhebung interprétative. A travers une telle interprétation, l'espace s'est doté de ce que l'on pourrait appeler un "surplus" de signifiés, un processus de "saturation symbolique".

Si Yan'an et Tiananmen furent semblables dans la mesure où chacun représenta une rupture historique et culturelle, ce fut Yan'an qui constitua le point de transition non seulement dans les luttes du PCC contre ses ennemis mais également dans les luttes des factions à l'intérieur du parti lui même. Tiananmen symbolisa lui les exigences pour un changement et une succession générationnels, partie plus large d'une transition des valeurs politiques, mettant l'accent sur les droits individuels, une structure légale plus "permissive", un pluralisme et une responsabilité politique, c'est à dire tous les principes dont la validité était déniée dans Yan'an où l'accent était mis au contraire sur le communautaire, le collectif et où la démocratie était définie comme une variante de la volonté générale rousseauiste. Yan'an devint un simulacre pour le socialisme chinois, Tiananmen est un simulacre pour la démocratie chinoise. Le premier s'incarna dans une communauté utopique construite dans des conditions de chaos et de violence et chercha à transcender les deux dans un ordre nouveau. L'autre fut improvisé, constitué à la hâte, transitoire, mais fabriquant une communauté temporaire, qui révéla l'ampleur de la crainte que nourrissaient les gens à l'égard de l'Etat et l'étendue de leur méfiance à l'égard du Parti. Les deux événements redéfinirent un territoire 
géographique, un espace, ils délimitérent un terrain en le détournant de ses usages habituels. A l'intérieur de chacun de ces espaces, on mena une politique de mobilisation et de confrontation, on joua sur une sémiotique de la présentation, du spectacle, du théâtre, avec, dans les deux cas, une direction du mouvement extraordinairement sensible à l'usage des mots, des images, et de l'orchestration symbolique ${ }^{5}$. Dans les deux cas, l'oralité précéda la textualité, le discours politique émergeant au sein de "l'agora", de l'espace public, espace à portée du son de la seule voix humaine, le son lui même créant une sensation d'intimité politique.

Problématique Dans cet article, j'ai voulu présenter la discussion en quatre parties plus ou moins bien reliées entre elles. La première applique certaines catégories d'analyse au rôle de Mao en tant que "faiseur de mythe", de conteur, d'architecte moral, créant à la fois la logique et le texte de la révolution. La seconde partie décrit structurellement Yan'an et la place Tiananmen comme des centres symboliques et des moments moraux. Néanmoins, les deux cas nécessitent d'être resitués dans leur contexte historique respectif, et plus spécifiquement dans le cas de Yan'an, il est nécessaire d'analyser quatre des luttes pour le pouvoir "menées" par Mao, dans la mesure où elles ne furent pas en tant que telles des luttes comme les autres. Elles s'articulèrent sur la prétention au monopole d'un "cosmos" défini par Mao lui-même autour d'une idéologie (le marxisme sinisé), d'un pouvoir de domination militaire, d'un pouvoir administratif, et d'un pouvoir intellectuel. Mao utilisa en effet ces quatre dimensions pour asseoir son autorité avec un savant mélange de finesse analytique et tactique que l'on retrouve aussi dans ses textes. Mais il se heurta à des compétiteurs. Aussi chacune de ces luttes révéle-t-elle une dimension différente du processus de monopolisation. Chacune était nécessaire mais même ensemble, elles étaient insuffisantes, en l'absence de l'ingrédient final qui nous intéresse ici, le capital symbolique ${ }^{6}$. Nous discuterons dans dernière partie du déclin du capital symbolique attaché à Yan'an, dont la "forme congelée" servit de mythe légitimant l'Etat, et de la réapparition sous une nouvelle forme d'un capital symbolique sur la Place Tiananmen lors de l'insurrection étudiante. Le plan suivant constitue une procédure d'analyse qui va donc du plus abstrait au plus concret, qui va de Mao comme narrateur et agent cosmocratique, à Yan'an comme communauté utopique, république éducative dans laquelle les principes délivrés par Mao étaient traduits dans une relation institutionnelle spéciale entre éducation, principe moral, justice et vertu. Seulement, je veux montrer qu'au sein de cette haute raison morale Mao exerça un pouvoir coercitif si brutal qu'il révèle la "dureté" de Yan'an au sein même de la figure utopique ${ }^{7}$. En définitive, si l'on peut dire à propos de Yan'an que le discours politique a produit du capital symbolique sous la forme d'une synthèse morale chinoise indépendante (en dépit des prétentions et des faux-semblants à l'égard du au marxisme), la ritualisation et la formalisation de ce capital l'ont érodé à un tel point que "l'espace" moral nécessaire à une place Tiananmen avait été aménagé bien avant que les événements de la place n'aient réellement lieu\&.

11 Le discours comme pouvoir Le discours comme pouvoir, est une problématique décrivant à la fois un phénomène, celui de la constitution d'un capital symbolique, et posant un problème méthodologique au niveau de l'analyse des relations entre discours et pouvoir. Cette problématique se présente sur le plan de la méthode comme une alternative aux catégories fourre-tout, surchargées de sens, qu'utilise la science politique : "culture", "nationalisme", "idéologie", et surtout "charisme". En effet ces dernières catégories expliquant tout, n'expliquent rien. Elles constituent des substituts à la connaissance. Nous voulons montrer ici leur faiblesse explicative et faire exploser 
de tels termes afin de voir les éléments qui se cachent derrière de telles appellations. C'est là un avantage de l'approche ethnographique. L'accent est mis aussi bien sur le point de vue de l'intérieur que de l'extérieur, sur la perspective des participants que sur celle de l'observateur.

Trois méthodes: structurale, herméneutique, exégétique Pour cela, trois méthodes seront utilisées. La méthode structurale (une mytho-logique), la méthode phénoménologique (une interprétation partagée de l'expérience), et la méthode herméneutique (une plongée collective dans les textes qui deviennent hégémoniques) 9 . D'un point de vue théorique, chaque approche est plus ou moins autonome, plus ou moins marquée par ses origines. Appliquer la méthode structurale à Yan'an permet de l'examiner comme un texte social qui est enchassé dans trois narrations, un récit long, un récit médian, et un récit court, les événements de ces récits pouvant être lus de deux manières, premièrement comme métaphore ; deuxièmement comme métonymie ${ }^{10}$. La méthode phénoménologique appréhende elle l'univers des interprétations et des intentions des acteurs résultant des événements de ces récits vécus en tant qu'expérience. La méthode herméneutique traite quant à elle de la traduction des récits et des expériences en textes, en un corpus complet, incorporant l'autorité, et résolvant logiquement la tension inhérente entre les affirmations de principe issues de la méthode dialectique et la coercition brutale issue de la praxis de l'action instrumentale. En effet, à Yan'an, la "plénitude achevée" et "l'instrumental" étaient tellement imbriqués qu'ils finirent par représenter "une unité des contraires", une caractéristique du communisme chinois dont la relation a fluctué en fonction des changements dans le parti et des situations auxquelles il a été confronté ${ }^{11}$. C'est précisément cette unité des contraires qui fut rompue, qui explosa Place Tiananmen. Et cette rupture fut définitive lorsque les vieux Yan'anites eurent recours à une coercition impitoyable sans même arguer d'un quelconque principe, juste au moment où les étudiants et les partisans de la Nouvelle Démocratie en appelaient au contraire à de grands principes en l'absence d'autres formes de pouvoir. C'est là que l'on peut voir dans cet univers miniaturisé de Tiananmen une société en gestation plutôt qu'un modèle alternatif d'Etat.

Nous allons appliquer les trois méthodes à Yan'an afin de l'analyser au moment où il devint le noyau dur du mouvement communiste chinois et le moment moral par excellence de la révolution. Nous verrons que Yan'an constitue également une rupture marquant la transition entre un parti clandestin, marginal, miné par les factions et les rivalités internes, et un mouvement révolutionnaire entièrement mobilisé. Yan'an recouvra le passé, pôle négatif qui devait être transcendé, et redéfinit le futur aux moyens tant d'une logique que d'une praxis correspondant à une nouvelle étape, dont les objectifs furent de résoudre les luttes factionnelles aiguës au sein du PCC (incluant également les luttes provenant de l'importation au sein du parti chinois des conflits existant dans le parti communiste soviétique). Le contexte plus large fut celui du conflit avec les nationalistes, présenté comme la vérité de l'Histoire, et marquant la voie nécessaire du passé vers le présent. La tâche la plus immédiate fut la guerre avec les Japonais. Ceci permit de fixer trois objectifs bien définis : inscrire localement la vérité marxiste, préciser la juste ligne, et déterminer la logique de cette vérité à travers la dialectique de classe et la récupération de la souveraineté nationale au moyen d'une méthode doctrinale unique. Chaque lutte apporta à l'ensemble des idéaux et des idées révolutionnaires abstraits une dimension spécifique nécessaire - une "théorie de la 
pratique" incorporée dans les stratégies, lesquelles combinaient l'intentionnalité passionnée de la révolution chinoise elle-même, avec la rationalité de la survie.

Une invention: le lien exégétique Si l'on insiste tant sur le symbolique, c'est pour montrer entre autres qu'il est nécessaire de créer une communauté politique dans des conditions de chaos virtuel. Plus communément, et l'expérience le confirme partout en Chine, les circonstances d'un danger exceptionnel détruisent toute confiance en l'avenir. Chaque personne doit survivre en agissant pour elle-même. Donc, dans un tel contexte, mobiliser et collectiviser, obligèrent Mao et ses camarades à transcender le hasard et à créer une logique d'ordre telle que les conditions du chaos lui-même deviennent au sein de celle-ci, les conditions de la transition vers l'ordre. C'est pour accomplir cette transformation du Chaos en Ordre qu'ils improvisèrent ce que j'ai appelé un lien exégétique. Il s'agissait d'une méthode d'instruction qui développa une interprétation commune des expériences partagées. Grâce à cette méthode, des solutions furent inventées et choisies au milieu du désespoir et on trouva des alternatives là où auparavant les gens n'en avaient aucune. Convertissant les défaites en leçons et les victoires en événements exceptionnels, Yan'an montre comment en politique (comme dans la vie personnelle) l'illusion partagée de possibilités crée la réalité de l'opportunité.

Combinaison d'une interprétation mythique et d'une logique éducative conduisant à une définition morale de la vérité, Yan'an fut l'instrument désigné pour s'opposer à l'environnement hostile, négatif, prédominant. Il a donné aux gens l'idée qu'ils pouvaient penser eux-mêmes au delà de leurs difficiles conditions de vie, et que quelle que soit la nature désespérée de la situation dans laquelle ils semblaient être, ils pouvaient, par l'interprétation, ouvrir l'histoire au moyen d'une clef dialectique, en résolvant de cette façon les contradictions de l'histoire en leur propre faveur. Dès le début, Yan'an ne fut jamais uniquement une base militaire, ou une zone frontalière sanctuaire, mais une communauté utopique, communauté exprimant un intense désir de changement politique, entrepris aussi bien au niveau de l'instruction politique que dans la conduite de la guerre et de la révolution ${ }^{12}$.

Mao, agent cosmocratique Avant de décrire Yan'an, je souhaiterais montrer le rôle clé joué par Mao dans la formation de ce qu'a été Yan'an. Il créa et joua plusieurs rôles cruciaux qui s'inscrivent dans le type d'analyse qui a été retenu ici. Il fut en premier lieu un narrateur, une figure de l'Odyssée, une figure en exil essayant de revendiquer un patrimoine perdu. Il fut ensuite un agent socratique, un enseignant, un théoricien, descendant putatif de Lénine (avec peut-être en plus une petite touche du premier empereur Ming). Il convient également de noter l'existence d'un Mao impitoyable, voire stalinien même, soigneusement déguisé derrière un rôle cosmocratique. Mao finit enfin en apothéose comme Lénine, embaumé, mannequin de cire dans un cercueil de verre exposé aux vues des visiteurs, les salles environnant sa dépouille remplies d'objets liés à la révolution. Et à la différence des mausolées des empereurs Ming qui firent édifier leurs tombes profondément sous terre, la crypte de Mao comme celle de Lénine, force au contraire l'attention ${ }^{13}$. Durant sa vie, Mao, en jouant tout ces rôles, fut capable à la fois de créer et de symboliser le discours hégémonique de la révolution chinoise comme l'unique culture politique possible. Par une narration sélective de l'histoire, il privilégia les revendications locales de ce qui commença par être un héritage marxiste intellectuel étranger ou extérieur ${ }^{14}$. Les revendications pressantes et le contexte marxiste plus large s'imbriquèrent dans l'organisation pratique de Yan'an, 
dont la structure de la vie militaire et sociale constitua une version sérieusement remaniée de la base initiale de Jianxi, avec un accent très important mis sur l'éducation, les institutions de recherches, l'apprentissage et le perfectionnement de soi. Aussi, dès le départ, ce fut Mao qui donna à Yan'an son sens le plus large comme si Yan'an était une sorte d'extension de sa propre personnalité, séduisant par là les candidats et impressionant ses propres suivants. Ce fut Mao qui créa le processus de lien exégétique et qui, avec quelques personnes de confiance, développa un lexique élaboré qui allait de pair avec ce processus. Grâce à cela, des acceptions spéciales furent liées à des signes, à des mots révolutionnaires, à des insignes, lesquels, incorporés à leur tour dans les mythes, les histoires, les textes, attirèrent à eux essentiellement un type de révolutionnaire jeune et romantique disposé à affronter l'agonie, les blessures et la mort.

Mao fut probablement en cela beaucoup moins marxiste que la plupart des intellectuels qui avaient été les chefs du parti avant lui. Il fut plus un improvisateur ayant la capacité exceptionnelle de convertir l'oralité en texte, aussi bien dans l'immédiateté des événements, qu'en second lieu par la réécriture en termes de principes universels. Il employa autour de lui à cet effet une bande d'intellectuels activistes, partageant tous la rude et difficile vie des cavernes de Yan'an ${ }^{15}$, combattant et vivant une existence fruste, et très différents de la notion classique de l'intellectuel chinois. Au même moment, il se présenta lui même comme un théoricien accompli, maîtrisant la théorie avec aisance, calligraphe, poète, mais également chef politique à l'esprit inflexible. Il avait pris par exemple l'habitude de tomber malade quand il ne parvenait pas à ses fins, et essayer d'éviter d'apparaître impitoyable alors que ceci était intrinséquement lié à sa notion de l'obligation révolutionnaire. Le mandarinat de Yan'an qui formait une tribune autour de Mao fut constitué d'ascètes révolutionnaires puritains qui attirèrent nombre de personnes qui, manquaient peut-être d'hubris révolutionnaire, mais qui devinrent disposées à se mettre au service de la révolution et de la guerre anti-japonaise ${ }^{16}$. Et dans la mort, les restes de Mao embaumé continuèrent de porter en eux cette permanence de la révolution comme une nouvelle tribune.

Mao au centre de Yan'an L'espace situé sur les hautes terres peu hospitalières des collines de loess de Yan'an ne peut que faire penser l'observateur à une "république des cavernes", à une république "platonicienne". Là bas, la logique dialectique fut associée à la dérivation de vérités plus que d'opinions, et l'organisation sociale égalitaire masqua des hiérarchies fonctionnelles différenciées sur la base de l'éducation. Là bas, on instaura également une distinction entre les classes permises et les classes exclues, la vertu étant ancrée dans la classe montante. Là bas, la justice comme but d'une pratique de la théorie, permit à la fois d'accroître la portée du sens et de l'organisation de son code et surtout donna aux mots leur capacité performative. Quant à la théorie elle-même, parmi ses objectifs explicitement définis, l'on trouvait un processus d'ordonnancement mental, un achèvement des esprits au delà de la matière par le dépassement des contradictions apparentes. Yan'an offrit ainsi un levier d'Archimède pour le triomphe du projet moral révolutionnaire, et en fut la tribune, la scène ${ }^{17}$. Le Parti communiste chinois se présenta lui même comme un Etat en devenir, ayant Mao comme agent, et sa logique comme force motrice du changement. En redéfinissant la nature du parti et le caractère moral de l'Etat, il devint acceptable que l'évolution des forces de production puissent être reconceptualisées afin d'éliminer à terme les 
relations de classe dans les rapports sociaux de production, but non seulement logique en terme de théorie mais cohérent avec la vision millénariste en terme de révolution.

$\mathrm{Au}$ centre, donc, Mao Zedong comme narrateur, faiseur de mythe, logicien et philosophe roi, redécouvre le passé et par un processus d'inversion dialectique le convertit en une projection millénariste de vérité et de vertu. Interprétant ainsi les expériences concrètes au travers d'un mécanisme éducatif élaboré, Mao est à même de redéfinir le caractère $\mathrm{du} \mathrm{PCC}$ en fonction de ses propres desseins. Son projet révolutionnaire transcendant ou "triomphant" a alors trois objectifs: vaincre et éliminer les ennemis intérieurs, triompher du Guomindang, malgré la prétendue alliance avec lui, et détruire les Japonais. Mais, bien sûr, il existe beaucoup d'autres objectifs imbriqués au sein de ces trois là. Mao, le narrateur, les fait émerger si nécessaire et mobilise la mémoire de son côté en redécouvrant les rébellions et les révoltes paysannes antérieures. Mao applique la logique dialectique et objective la transformation de l'histoire en réalisation d'un millenium révolutionnaire. Il atteint de cette façon une vision morale qu'il prétend supérieure. Quant à la Chine, Mao la dépeint comme un pays perdu, comme l'histoire d'un déclin. Il prescrit alors les conditions nécessaires à la restauration d'un nouvel état de grâce : les patrimoines perdus seront rachetés ou récupérés par une expropriation des expropriateurs. La première chose, sera de restituer aux paysans les terres laissées aux propriétaires fonciers. La seconde sera de redonner à la nation la souveraineté abandonnée aux étrangers. On le voit Yan'an, n'est ni simplement une des 19 régions frontalières, ni même une "capitale" normale. Yan'an devient la capitale parce qu'en ce lieu est le centre moral de la révolution, non l'inverse. C'est là qu'on peut trouver le Comité central et Mao, et c'est là que les discours et les oeuvres de la pensée Mao Zédong ont finit par former un corpus autonome ${ }^{18}$.

20 Yan'an fut donc un discours-communauté dont l'objet était de remplacer le discours chinois conventionnel en réalisant une inversion des hiérarchies et des hégémonies prédominantes ancrées dans ce vieux discours ${ }^{19}$. Les mots et la langue furent, à cet égard et plus que toute autre chose, d'une importance cruciale. Ils furent plus importants encore que dans toute autre version du marxisme dans la mesure où ils portèrent la marque personnelle de Mao. Etroitement encadré par des textes clefs qui lui donnaient des caractéristiques plus ou moins sacrées, le discours permit de distinguer les indigènes, des étrangers. Comme tout langage il sépara les gens mais de surcroît, Yan'an combina avec succès la linguistique "de l'altérité" avec la notion de vérité révélée. Ceux qui entraient à Yan'an jouirent donc d'un certain privilège moral et intellectuel. Même les épithètes utilisées par les ennemis de Yan'an pour décrire ceux qui y vivaient, "bandits rouges" par exemple, devinrent la preuve de vertus morales supérieures à la Robin des bois, et un ancien "bandit" comme He Long devint le prototype même du chef héroïque de l'armée rouge.

21 Le maoisme comme idéalisme Imbriqué dans un discours total, un espace communicationnel fut établi sur le terrain de Yan'an, c'est à dire à l'intérieur même de la géographie physique de Yan'an ; et ce champ était si puissant qu'il permit au PCC de vaincre en dépit de la faiblesse relative de ses forces et des conditions défavorables ${ }^{20}$ à son arrivée au pouvoir. Pour construire ce discours, Mao créa une grammaire politique, établissant sa structure et sa terminologie à partir de nombreuses sources, aussi bien chinoises que marxistes, et lui donna une structure logique à partir de sa propre interprétation de la dialectique. Il revendiqua une filiation avec Marx (ou mieux avec le 
léninisme et le stalinisme) et plaça à l'intérieur d'un édifice hautement rationaliste constitué par quelques unes de leurs idées un noyau hautement non rationaliste, moral, fictif, et évocateur, mais tout autant impitoyable. Donnant sa propre notion de la rationalité, laquelle était très éloignée, différente et antagoniste des interprétations libérales, la version de Mao prétendit à la vérité en considérant que celle-ci dérivait de sa dialectique et que les événements avaient leur propre nécessité logique. Incorporé dans un programme de transformation vers le "socialisme de développement", ce qui était des fables améliorées devint des "vérités de l'histoire". Ce qui apparut comme fondé en logique fut en fait une profession de foi ${ }^{21}$.

Tout comme avec les autres variantes du marxisme, le point de départ du maoisme repose sur l'interprétation de circonstances et d'événements facilement reconnaissables, et le maoïsme partage avec ces autres variantes le fait qu'il constitue avant tout une théorie critique. Toutes ces versions pointent les injustices structurelles manifestes en associant avec perspicacité les causes et les effets mais ne donnent pas d'instructions à l'égard du pouvoir d'Etat. Et c'est précisément ici, parce que le marxisme classique définit très peu le socialisme que les chefs politiques marxistes trouvent un espace discrétionnaire. En l'absence d'un système de règles et d'institutions de gouvernement spécifiquement socialistes, réussir pour le marxisme signifie établir une structure normative permettant une improvisation politique, justifier une pratique au nom de principes. Le marxisme qui prétend être le matérialisme ultime, est en fait dans ce sens l'idéalisme ultime.

Yan'an : lieu d'accumulation du capital symbolique

Ceci caractérise parfaitement ce qui s'est passé à Yan'an. Yan'an est né de faits concrets et d'expériences hautement dramatiques, dans un contexte de campagnes d'extermination du GMD, de lutte avec les Japonais, et dans le contexte de la longue Marche elle-même. Yan'an lança des projets idéalistes, et chacun de ces projets fut "matérialisé". Dans ce processus chaque chose banale fut touchée par le sacré : la nourriture, l'abri, les corps, la sexualité, la production, la consommation, l'organisation militaire et civile. La lutte des classes et la guerre ajoutèrent un contexte de réalisme situationniste. Tout fut explicitement doté d'une signification éthique. L'action devint exemplaire. Tout le monde devenait l'exemple de quelque chose ${ }^{22}$.

Cependant, dans la mesure où les vérités doivent apparaître comme universelles, leur articulation pouvait donner l'impression d'avoir été inspirée par Mao seul. On insista alors avec force sur la dimension collective du discours. Le rôle de Mao était uniquement d'exprimer une conscience émergente et généralisée, laquelle était l'oeuvre et restait la seule possession de la classe marginalisée dans son ensemble classe d'ailleurs plus paysanne que prolétaire, et comprenant "le lumpen" (que Marx considérait avec mépris). Ce qui, à cet égard, rapproche plus le maoisme de l'anarchisme que du marxisme ${ }^{23}$. Dans la cosmologie de Mao, ce dernier se présenta toujours lui-même comme le simple porte-parole de la classe marginalisée, et non comme une force indépendante, le président d'un parti effectuant le lien crucial entre la doctrine et la classe. En somme, ce pouvoir discrétionnaire par rapport à Marx qu'il exerçait effectivement reposa sur son habileté à faire apparaitre le mythe non seulement comme logique mais acceptable comme réalité. Cela peut aussi s'expliquer non pas tant par la qualité du marxisme de Mao que par l'ingéniosité née de son inquiétude politique, de son désir d'atteindre le sommet de la société pour mettre le monde sens dessus-dessous. Moins la théorie fut effectivement approfondie, plus elle 
sembla tout justifier. En bref, Mao institua pour lui-même une position indépendante dans l'histoire, tout en se présentant simultanément et simplement comme son agent, ou pour le dire plus symboliquement, il joua dans un premier temps le rôle d'un chinois odysséen, vagabond en exil cherchant à sauver le patrimoine de son pays, et narrateur plaidant ses causes en gagnant de la sagesse; une fois la sagesse acquise il devint un Socrate chinois appliquant la logique dialectique à la rationalité du millénaire ${ }^{24}$.

Trois récits Les événements de chaque récit contiennent les leçons de cette sagesse, leçons qui devaient être enseignées, apprises et préservées au sein de la méthode dialectique. C'est ici que la dimension socratique se rapproche de celle de Mao l'éducateur, de Mao le philosophe roi ${ }^{25}$. L'éducateur a un rôle spécial dans la société chinoise. Il est aussi un narrateur. Mao fut l'un des plus grands narrateurs d'un pays où pourtant l'histoire orale a une longue et riche histoire. Il présenta sa version de l'histoire chinoise comme l'histoire d'une chute, d'un déclin en l'incluant dans un récit qui s'étendait sur la longue durée : commencant par les guerres de l'opium, décrivant la rébellion de Taiping et l'histoire de la rébellion paysanne, intègrant la chute des Qing, et se terminant sur le Chaos fondamental. Dans le récit intermédiaire des luttes entre le Parti communiste et le Guomindang à propos de la doctrine et du pouvoir, pour savoir qui allait hériter de l'héritage de Sun Yat Sen, Mao devint non seulement un narrateur mais aussi le chef de file de sa propre histoire. C'est à cette occasion que l'on trouve un autre récit enchassé dans celui-ci : celui de l'ascension de Mao, un Mao transcendé réussissant à dépasser les conflits fratricides aigus entre les factions du PCC. Dans le récit de longue durée, Mao n'a pas de rôle spécifique mais un espace est créé pour lui. Dans le récit intermédiaire, son rôle devient important. Et dans le récit de l'histoire courte, Mao lui même devient central.

L'enchassement des récits et la constitution du capital symbolique Ces récits s'enchâssent entre eux comme les parties d'un téléobjectif. Plus l'objectif est ouvert, plus grosse est l'image, mais plus petit est le champ. Lors de la mise au point, afin d'obtenir une image nette et agrandie de Mao, une condensation et une intensification symboliques s'opèrent. Tout ce qui est en dehors du champ visuel de l'objectif est incorporé dans la figure au centre de l'objectif . L'intensification et la condensation sont les deux ingrédients politiques cruciaux du capital symbolique.

Ceci parait bien sûr terriblement abstrait. Mais en pratique c'est assez concret. Ces récits et narrations sont connus à l'avance. Ils prennent place dans un contexte de luttes spécifiques dont tous les participants ont directement ou indirectement l'expérience. Parmi les plus importants récits figurent ceux qui ont permis à Mao de montrer la marche nécessaire du pouvoir politique et de l'incorporer dans un récit qui comprend la trahison du PCC par le Guomindang en 1927, la révolte de Nanchang, le soulèvement de la Moisson d'Automne, la Longue Marche, sans parler des conflits l'opposant à Zhang Guotoa, Liu Zhidan, Wang Shiwei et Wang Ming, chacun de ces micro récits s'enchassant dans une vision plus vaste. Ces récits font partie des quelques "faits" qui ont constitué le programme des campagnes de rectification, en tant que faits mythiques qui se devaient d'être expliqués par la méthode dialectique. C'est dans ce sens que cette "mytho-logique" sert de fondement au lien exégétique, de procès établissant la Pensée Mao Zédong comme la voie menant à une existence sociale supérieure et plus vertueuse. Elle masque également la brutalité de la course au pouvoir et la dureté de la morale du commandement en général. Cette brutalité est plus particulièrement perceptible aujourd'hui, dans la mesure où les chefs politiques 
principaux qui sont au pouvoir sont les produits du système mais ont perdu du capital symbolique. Les vieux Yan'anites au plus haut niveau, comme survivants des luttes doctrinales, de la torture et des meurtres au sein du Parti communiste, et de la lutte contre les nationalistes et les japonais, sont simplement maintenant des praticiens expérimentés nourrissant peu d'illusions sur l'exercice du pouvoir.

La réduction des conflits par l'unanimisme du maoisme L'une des réalisations les plus significatives de Mao à Yan'an fut d'avoir mis fin à l'un des plus terribles conflits fratricides à l'intérieur du parti qui conduisit à la torture et à la mort de milliers de membres du parti qui se trouvaient du mauvais côté de la "ligne" du Parti. Le cas le plus célèbre fut l'incident de Futian en 1930, mais de tels événements furent chose courante durant ces années[On a tendance à oublier combien furent âpres les conflits fratricides au sein du Parti communiste chinois dès les premiers jours de son existence. Les gens dans chaque faction savaient et tenaient pour véridique la version officielle staliniste d'activités anti-parti. Ils acceptèrent le rôle de Radek comme étant l'assassin de Kirov, et considéraient comme une vérité que des Trotskystes comme Maring et ses successeurs (on ne parle pas de Borodin, Voitinsky, Roy, et d'autres qui rentrèrent en conflit avec Staline) étaient des traîtres à la révolution. Ils ont eux-mêmes participés aux pires intrigues aux côtés d'une faction ou d'une autre à l'intérieur du Parti Communiste Chinois, ils ont pu facilement projeté à partir de leurs expériences non seulement ce qui allait arrivé dans le Parti communiste soviétique, mais les effets de factions en Union soviétique sur la Chine. Les premiers communistes russes n'ont pas seulement aidé à créer le PCC, mais ont continué à jouer un rôle actif au sein du parti jusqu'à la création de Yan'an. De plus, les débats internes au parti à propos de la ligne politique à suivre ont été affectés par les théories de personnes comme Trotsky et Boukharine. Voir Léon Trostky, Problems of the Chinese Revolution, Ann Arbor, The University of Michigan Press, 1967. Pour une description des débuts du PCC voir Tony Saich, Maring's View of the Nationalist Movement in China, Amsterdam, Porill, 1992. Voir aussi Charles B. McLane, Soviet Policy and the Chinese Communists 1931-1946, New York, Columbia University Press, 1958, et John E. Rue, Mao Tse-tung in Opposition, Stanford, Stanford University Press, 1966, pp 204-312.]] . En revanche, à mesure que Yan'an devint une communauté utopique, une république éducative, et que tout le monde souscrit à la version de la volonté générale de Mao, les assassinats à l'intérieur du parti cessèrent.

30 En résumé, le marxisme est au mieux une théorie critique conduisant plus à une pratique innovante qu'à des solutions éprouvées. La pensée Mao Zédong est un dérivé du marxisme qui est plus axée sur la pratique que la théorie. C'est en fait "une théorie de la pratique" pour reprendre le terme utilisé par Pierre Bourdieu, moins intéressante que celle de Lénine, totalement pragmatique comme celle de Staline, et plus chinoise qu'autre chose. Mao pour constituer ce corpus choisit certains textes, les siens bien sûr et certains autres dont les "classiques" du marxisme, pour qu'ils soient médités et étudiés par les membres de la communauté, ainsi que par les cadres supérieurs; étude qu'il leur fallut faire en suivant la méthode prescrite, c'est à dire en en faisant des exercices de dévotion. Les principes organisationnels suivirent les bases de l'éducation. L'accent fut mis sur la rationalité, la maîtrise de soi et la discipline collective. C'est pour cette raison que l'on peut parler à propos de Yan'an de communauté utopique, ou du moins d'un simulacre (plus que d'un modèle) de communauté où les participants étaient dotés de pouvoirs presque magiques issus de l'incantation des mots, et dont la 
fonction était non seulement de permettre la poursuite vigoureuse de la guerre et de la révolution, mais d'être l'instrument choisi des plus hautes vérités ${ }^{26}$.

31 Le dépérissement du pouvoir des mots Ce discours de communauté fut en fait l'accomplissement momentané de Yan'an. Pour l'analyser encore plus précisément, nous devons utiliser les trois modes d'analyse décrits précédemment, et les appliquer aux matériels provenant d'entretiens et d'enregistrements retranscrits. Il est possible à l'aide de notions telles que discours de communauté, lien exégétique et capital symbolique de voir comment les nouvelles croyances politiques de Yan'an s'articulèrent, comment un nouvel ordonnancement conceptuel fut superposé au chaos prédominant, la guerre et la terreur avec une vivacité et une force étonnantes. Le caractère inévitablement fragile d'une telle vivacité et d'une telle force sera facilement admis. Le pouvoir du sens est toujours momentané. Les vérités politiques dépérissent à l'usage. Les efforts entrepris pour les soutenir aux moyens d'une politique répressive accélèrent le processus de déclin en ouvrant la porte aux abus. Néanmoins, le marxisme de Mao a, pendant un bref moment historique, brillé d'un éclat considérable. Constituant le "moment moral" de la révolution, son capital symbolique fut constitué pour servir à la fois comme une alternative au capital économique et comme son équivalent fonctionnel ${ }^{27}$.

32 En utilisant ces concepts, nous voulons maintenant examiner ce qui a fait que Yan'an est devenu ce moment moral par excellence. Nous voulons montrer cette dimension en analysant à partir des entretiens contemporains, comment, en effectuant un retour sur leur passé, ces personnes se sont perçues à l'époque ${ }^{28}$. Une telle reconstruction de leur vie, de leurs manières de faire, de l'époque demeure difficile car en Chine plus qu'ailleurs, les événements continuent de s'imposer au passé.

La république des cavernes Structurellement, nous l'avons vu, Yan'an constitue une "mytho-logique", une communauté utopique qui, en son temps et pour ses propres membres, leur permit de croire que tous les événements des montagnes de Jinggaan à la Longue Marche était une série de miracles dûs au PCC; miracles en attente d'explications, vérités devant être validées par l'interprétation de l'expérience. Ce fut donc un monde d'intentions et de buts bien définis, allant du plus tactique au plus général et au plus théorique. La théorie était enchâssée dans la praxis militaire, administrative, productive, artistique, littéraire, éducative, etc., et s'appliquait à une communauté politique très réaliste, terre à terre, dont les habitants vivaient pour la plupart dans des cavernes, à l'intérieur de la terre elle-même. Toutefois, Yan'an fut plus concrètement un lieu de repos, entre l'exil et le retour, la défaite et le pouvoir. Ancien centre commercial clos par un mur d'enceinte sur la vieille Route de la Soie, ce fut ici, que les restes des armées du premier et second fronts qui avaient survécu à la Longue Marche s'installèrent dans les cavernes (la plus puissante des armées, l'armée du quatrième front établissant sa propre base ailleurs) ${ }^{29}$. Parmi les caractéristiques qui ont fait l'originalité de Yan'an, le caractère proprement miraculeux des survivants de la Longue Marche est prépondérant, les survivants transférant à Yan'an même, cette caractéristique qui les définissait ${ }^{30}$. En effet parvenant à la fin d'une telle "traversée biblique", ils conférèrent à Yan'an le caractère d'une terre promise, d'une nouvelle Jérusalem ${ }^{31}$. Mais ce n'était sûrement pas un pays où coulaient le lait et le miel. C'était en effet l'un des endroits les plus pauvres et les plus inhospitaliers que l'on pouvait imaginer pour la création d'une communauté utopique. Seulement grâce à de notables efforts de volonté et de détermination, les gens purent y survive et même y prospérer. 
L'existence de Yan'an apparut comme un miracle. Et effectivement, devenir une république éducative, une communauté de communicateurs, en dépit de ces rudes conditions, fut réellement extraordinaire ${ }^{32}$.

Les origines de Yan'an Yan'an désigne géographiquement une unité administrative frontalière sous l'autorité technique du gouvernement nationaliste de Chiang Kai Shek. Mais dans la pratique, ce fut un territoire autonome ${ }^{33}$. Constitué des parties de trois régions du nord-ouest de la Chine, Shaanxi, Gansu, et Ningxia, c'est là que Mao et son groupe de survivants battirent en retraite après une série de désastres militaires dont le point culminant fut marqué par la perte de la base de Jiangxi qui précipita la Longue Marche. Soviet local à l'origine, sous le commandement de Liu Zhidan et Gao Gang, deux éminents commandants de la guérilla, la zone elle-même était très pauvre. Elle était située à un coude de la Rivière jaune sur un plateau de loess, s'étendant sur 450 kilomètres du Nord au Sud, et sur 400 kilomètres d'Est en Ouest. Comparé à la base initiale de Jiangxi d'où vinrent les survivants, les autorités de Yan'an étaient beaucoup moins rigoristes, transigeant avec les intérêts des paysans locaux, particulièrement en ce qui concerne la gestion des terres et les problèmes liés à la famille tel que le divorce $^{34}$. Il existait 19 autres unités frontalières du PCC. Les deux plus importantes après Yan'an, connu aussi sous le nom de Shaan-Gan-Ning (Shaanxi, Gansu, et Ningxia), furent sans doute Jin-Cha-Ji (Shanxi, Chahar, et Hebei) et Jin-Ji-Lu (constituées de parties de Shanxi, Hebei, Shandong, et Henan). Shaan-Gan-Ning (que nous désignerons sous le nom de Yan'an) ne fut pas nécessairement la plus significative militairement ${ }^{35}$, mais elle fut donc la Nouvelle Jérusalem du mouvement communiste. Yan'an avait été une base de guérilla communiste avant même l'arrivée de Mao bien qu'aucun de ses chefs, Liu Zhidan et Gao Gang, n'ait été partisan de la faction de Mao. Ce dernier établit d'ailleurs son premier quartier général, non dans la ville de Yan'an mais à Bao'an (dans Shaanxi) en janvier 1935 après avoir pris le contrôle du Parti dans Zunyi ${ }^{36}$. Peu après il déplaça son quartier général dans la ville de Yan'an. Elle devint rapidement un aimant attirant, de partout, les jeunes chinois qui voulaient combattre les Japonais. Après l'incident de Xian en 1936 qui vit la capture de Chang Kai Shek et sa libération sous réserve de son accord avec les principes d'un front uni contre les Japonais, Yan'an fut encore beaucoup plus connu. Jusqu'en 1937 une atmosphère de relative tolérance politique prévalut. Après, Mao Zédong fut davantage concerné par les règles de gouvernement des zones sous le contrôle direct du PCC, mais également des autres zones, situées derrière les lignes ennemies. Il reconnut que l'autorité dépendrait de la consistance doctrinale et militante. Alors qu'il commençait à développer ses idées il commença à modifier certains des principes auxquels il avait auparavant adhéré. Par exemple, dans la mesure où il était devenu nécessaire de gagner la confiance des paysans, la définition de l'ennemi de classe changeat, devenant beaucoup moins exclusive que ce ne fut le cas au départ. Il en fut de même en matière de droit de propriété, de divorce et de toutes les autres questions relatives à la famille ${ }^{37}$. Yan'an fut construit durant la période la plus difficile de la révolution alors que les forces militaires communistes étaient complètement désunies. L'organisation du Parti fut véritablement ad hoc et improvisée. Les soldats étaient fidèles à des commandants militaires différents, qui n'étaient pas tous fidèles à Mao, loin de là. Les gens avaient tendance à suivre une ligne politique générale de gauche, de façon plus ou moins idiosyncrasique. La spontanéité était importante chez des personnes se proposant de construire des grottes, des routes, de confectionner leurs propres vêtements, de faire pousser leur propre nourriture, etc. Des ateliers militaires furent construits et des 
arsenaux érigés de façon à pouvoir être dissimulés en un instant en cas d'attaque japonaise. L'équipement était si antique et les installations pour la production d'armes si primitives qu'il était nécessaire d'aller à la chasse à l'ennemi pour obtenir du matériel. Les tactiques militaires durent être adaptées aux forces incontestablement supérieures du Guomindang et des Japonais. Aussi, de nouveaux principes d'organisation furent-ils développés, les unités de l'armée furent dissoutes et recomposées, des guérillas armées autonomes furent organisées derrière les lignes ennemies, afin d'être capables d'y vivre comme un poisson dans l'eau. Mais vivre comme un poisson dans l'eau, nécessite de fait, des relations prudentes et très soignées avec les paysans, ce qui fut fait et est exemplaire surtout en comparaison du Guomindang, (il s'agit sans doute des leçons des Montagnes de Jinggaan). Il fut donc nécessaire de laisser une grande marge de manoeuvre au groupe des commandants (dans leurs étroites relations avec les habitants des villes et villages) tout en les empêchant de contester et de défier au centre l'autorité du parti. Des programmes politiques et des gouvernements locaux furent instaurés, s'assurant ainsi que les habitants des villages resteraient de leurs côtés, et serviraient de relais de renseignement fiables. Mais ceci impliqua alors de procurer des terres aux paysans sans détruire complètement le système de propriété foncière car on risquait ce faisant d'aller au désastre économique. Maintenir la discipline était une tâche déterminante. Politiquement c'était le travail du parti. Travaillant au sein de la structure du mouvement de la "nouvelle démocratie" le principe d'action consistait à localiser une manifestation de "la volonté générale rousseauiste" aussi bien dans les villages, les districts, et les unités administratives plus grandes directement sous le contrôle du $\mathrm{PCC}$, que dans les unités administratives situées derrière les lignes ennemies ${ }^{38}$.

L'extension de Yan'an Lorsque les premiers Yan'anites furent rejoints par des milliers d'étudiants, d'enseignants, d'artistes, d'écrivains, de journalistes, de cadres de l'armée rouge provenant d'un peu partout, de paysans pauvres etc., un idéal plus ascétique commença à émerger, presque jésuitique, et d'un point de vue doctrinal plus sévère que celui qui prévalait jusque là. Une forte proportion des nouvelles recrues de Yan'an était constituée d'intellectuels (catégorie qui comprenait ceux qui avaient reçu une éducation scolaire de haut ou de moyen niveaux). Parmi ces derniers, nombreux étaient ceux qui avaient des opinions et des revendications radicales. Les plus jeunes étaient plus anti-japonais que prédisposés idéologiquement au marxisme. Ils considéraient le PCC comme la principale force combattant les envahisseurs japonais. De fait, "rejoindre la révolution" constituait pour nombre d'entre eux une démonstration de leur sentiment nationaliste plus que la réalisation de leurs idéaux radicaux. Cela ne signifie pas que les gens vinrent à Yan'an pour des raisons fortuites. En effet le voyage, à travers les lignes du Guomindang ou des Japonais, représentait déjà en lui-même un danger. Et chaque personne qui arrivait avait un récit à raconter. Une partie de l'alchimie de Yan'an s'opéra par le mélange de ces récits individuels avec les trois récits décrits précédemment. Chaque personne devint une partie significative de l'histoire. Ce faisant, cela permit d'embellir les événements grâce à l'interprétation. En 1940, il apparût clairement que Yan'an avait besoin d'un programme intellectuel, programme qui inclut la lecture d'importants épisodes historiques reliés aux événements présents en en faisant l'illustration des points de l'instruction théorique. A partir de cette fusion, d'austères leçons furent enseignées. Les gens furent mis en garde contre le libéralisme et les autres doctrines désavouées. On leur montra comment la dialectique pouvait être utilisée comme une épistémologie d'une stratégie de classe. Chaque acte prenait une 
signification plus morale que ne le laissaient supposer ses fonctions. Les règles de vie furent empreintes d'une densité symbolique. La vie collective fut donc essentiellement constituée par l'éducation. Les nouvelles recrues arrivant à Yan'an étaient habituellement logées à huit par caverne. Les couples mariés étaient souvent séparés. Les grandes cavernes qui donnaient sur une cour commune étaient réservées aux chefs des plus hauts rangs du parti, qui déplaçaient périodiquement leurs quartiers généraux d'une partie de Yan'an à une autre pour éviter les bombardements aériens. (Mao Zédong avait invariablement la plus grande caverne avec la plus belle vue). En plus des cavernes on trouvait des immeubles classiques. Deux de ces bâtiments constituaient de grandes salles d'assemblées, situé l'une aux faubourgs de la ville et l'autre en plein centre. Lors des réunions, les personnes rassemblées étaient installées en face des membres dirigeants du Comité Central. Tous portaient un uniforme. Lorsque le temps le permettait, les réunions d'études se tenaient dehors. Bien avant même, l'aménagement définitif de Yan'an, Mao avait commencé à consolider son autorité au moyen d'une réorganisation radicale des forces militaires, politiques, et productives. Celles qui autrefois étaient fidèles et sous les ordres des commandants et des commissaires de l'armée, qui avaient été identifiés à l'origine aux factions du parti hostiles à Mao furent restructurées à travers les institutions éducatives et les "universités". La conscience politique et la fidélité doctrinale furent tour à tour renforcées par un processus complet de rééducation. L'organisation de Yan'an demeura "civile et militaire" au sein du parti (et fut symbolisée par le double déclin de l'autorité des commissaires politiques et des commandants), mais la structure se divisa pour les institutions éducatives, les "universités", les instituts, et les écoles. Même si Yan'an formait assurément un campus il régnait cependant comme une atmosphère de campement de type $\mathrm{YMCA}^{39}$. Les gens étaient sérieux et motivés. La vie était partagée entre le terrain de volley-ball, les exercices militaires, les représentations théâtrales, la salle de classe, les activités productives, les artistes et les écrivains (l'Académie Lu Xun des Arts jouant un rôle important). Après plusieurs mois d'entraînement, les gens étaient redéployés. Certains allaient comme travailleurs clandestins dans les zones blanches, les autres devenaient ouvriers du parti, soldats ou commandants dans la huitième armée de terre. D'autres tenaient des rôles dans l'éducation comme maître, artiste, auteur dramatique, musicien, etc. Tous s'occupaient de faire pousser et de cultiver leur propre nourriture, et confectionnaient aussi la plupart du temps leurs uniformes. Par cette intersection permanente entre différents rôles, les personnes pouvaient être facilement déplacées entre les positions organisationnelles au sein de la structure de commandement (commandant d'unité ou commissaire politique) et passaient d'enseignants à organisateur du parti dans un village... Ceux qui possédaient des talents particuliers pouvaient être affectés à des troupes d'opéra, de théâtre, effectuant des tournées dans les unités de milices et les régiments de travail. Un commandant de la guérilla de l'armée rouge pouvait servir de chef rédacteur dans la ville de Yan'an.

La Campagne de Rectification Au début l'atmosphère de cette république éducative était relativement tolérante et on ne pouvait pas encore parler de l'instauration systématique d'un discours de communauté, ou d'un programme explicite de lien exégétique, ou de la formation d'un capital symbolique. Mais tout commença à changer vers 1941. En février 1942, la première phase de la campagne de rectification débuta. Les rapports clés des conférences cruciales du moment furent publiés dans Liberation Daily. Vingt deux textes servirent de programme de base fondamental, comportant des 
indications quant à la politique à suivre (relatives à la conduite des membres du parti), qui n'étaient certes pas tous écrits par Mao. Ils comportaient, par exemple les textes de Liu Shaoxi intitulés "Comment être un bon communiste" et "A propos de la lutte interne du Parti", mais également celui de Chan Yun "Comment être membre du Parti Communiste". Seulement ces textes comportaient aussi les attaques de Mao sur les "trois vents diaboliques" : le subjectivisme dans l'étude, le sectarisme dans le travail du parti, le formalisme dans la propagande et sa mise en garde contre le "subjectivisme" et le "dogmatisme" des intellectuels, "l'empirisme" excessif des travailleurs du parti, le sectarisme et les tensions "entre l'individu et le parti, entre les cadres d'origine et les nouveaux cadres provenant de l'extérieur, entre les cadres des services de l'armée et les cadres des activités civiles. D'autres matériaux plus officiels c'est à dire stalinistes, comportaient l'histoire officielle du Parti communiste de l'URSS ${ }^{40}$.

L'objectif ostensible était de parvenir a un plus haut degré de conscience, assuré au moyen d'un langage commun, avec un entraînement en logique et littérature. Les textes essentiels incorporaient le discours approprié, et le discours devenait total. Les méthodes concrètes d'éducation étaient axées sur l'exégèse de ces textes, elle-même destinée à les faire intérioriser comme des objets essentiels indépendants contenant les principes du mouvement. Comme le discours prescrivait les procédures et la conduite à suivre pour parvenir à des rôles modèles, les personnes n'étaient pas seulement interchangeables entre les différents rôles mais également entre les différentes fonctions. Les organisations du parti étaient caractérisées par leur flexibilité, et non leur bureaucratie. Si le parti subissait des pertes en personnel, il n'était de fait jamais paralysé.

La rectification a frappé toutes les unités, les plus sévèrement touchées furent les écoles, les universités, les centres de recherche, et plus encore les instituts spécialisés et les programmes de formation. Kangda, l'université politique et militaire antijaponaise fut peut-être le cas le plus significatif. Elle disposait d'un campus à Yan'an mais également de douze autres filières. Elle fut responsable de la formation de peutêtre 100000 diplômés et fut conçue en partie sur le modèle de l'académie militaire de Whampoa, mais également sur celui de l'académie de l'Armée Rouge de Juichin. Cette dernière qui avait fait la Longue Marche, s'était réétablie d'elle-même comme Académie de l'armée du peuple chinois avant de fusionner avec le collège Armée rouge pour devenir Kangda ${ }^{41}$. La liste des conférenciers se lit comme un Who's Who de la direction communiste, comprenant Lin Bia, Zhang Wentien, Ai Siqi, Zhu De, etc. Mais c'est Mao qui émergea comme le dialecticien suprême. Certaines de ses conférences qui traduisaient ses idées en matière de stratégie et de tactique devinrent centrales dans le recueil de la Pensée Mao Zédong ${ }^{42}$.

Durant cette période un nombre impressionnant d'écrits furent publiés, virtuellement ils interprétaient tous des expériences dans lesquelles chacun reconnaissait sa première expérience ou une connaissance. L'expérience brute était chiffrée (codée) symboliquement au sein de récits et traduite en principes abstraits, en théories, qui étaient alors appliqués, immergés dans des campagnes concrètes, militaires, productive, etc. Chaque jour était une expérience d'exhortation. Virtuellement chaque discipline était traitée, du sublime au ridicule, des principes de la guérilla et de la guerre aux négociations avec les paysans, ou comment améliorer l'usage de la houe dans l'exploitation agricole. L'on trouvait au sein du même texte les références les plus spirituelles et un humour au ras des paquerettes. Les mythes narratifs qui 
incorporaient l'incertitude comme la fantaisie des forces naturelles procuraient maintenant le fondement pour les théories de la guerre des paysans, de la production, de l'organisation... une même logique se manifestait dans toutes les illustrations dialectiques du contrôle conceptuel. Durant la campagne de rectification, comme ces textes étaient étudiés par tout le monde, les principes furent systématiquement appliqués à toutes les activités : étude, apprentissage, campagne militaire, campagne de production, organisation de l'administration du village, l'établissement du système d'unité ou du système de danwei, l'implantation de branches des écoles et des universités dans les autres bases.

Dans la mesure où Yan'an était une base relativement petite, les discussions, les réunions se tinrent à portée du son de la voix de chacun comme dans l'ancienne agora grecque. Il en résulta que les capacités d'orateurs, de rhétorique d'élocution et la qualité de présentation théâtrale furent cruciales. Or certaines des idées les plus importantes de Mao furent exposées dans ses premiers discours. Les auditeurs étaient ainsi faits complices du récit, en le transposant par écrit, avec leurs plumes et encriers prêts à l'emploi. Passer de l'oralité à la textualité ne se résuma donc pas à une simple affaire d'écriture. C'était un acte de promulgation qui devenait un talent.

Dans ce sens Yan'an comme discours de communauté fut un lieu où le langage, le sens et la compréhension furent les objets d'une manipulation consciente - dans le dessein d'une inversion conceptuelle transformant le mandarinat confucéen en mandarinat communiste. En somme il fut une praxis devant être menée au sein de toutes les institutions, armée, parti, gouvernement, université, institut de recherche, et utilisant toutes sortes d'instruments, salles de classes, représentation théâtrales, musique, opéra et bien sûr journaux et livres, pour instituer un nouvel idéal d'Etat communiste vertueux prétendant que le rationnel est le réel et que le réel est rationnel.

Les vétérans interrogés décriront encore avec excitation comment on pouvait aller de la caverne à l'école, à l'université, ou à l'institut, de l'école public de Shaanxi à l'université des femmes, aux écoles spécialisées comme l'école des automobiles, à l'académie Lun Xun des arts, et à l'école centrale du Parti. Chaque personne pouvait évoluer dans sa propre voie. D'analphabète on pouvait acquérir l'éducation de base, à savoir lire et écrire mais également atteindre les questions idéologiques les plus subtiles du Narodisme, du marxisme orthodoxe, de l'économisme, du léninisme, du menshevisme et du trotskisme.

Nous avons déjà indiqué d'où viennent les participants au processus de rectification : ce sont des étudiants nationalistes voulant lutter contre les japonais, des intellectuels (où l'on retrouve toutes les formes de radicalisme: anarchistes, trotskistes ou stalinistes), de nouveaux cadres issus des familles paysannes ou de récents partisans du Guomintang convertis au communisme. Ils sont tous passés par cette expérience du lien exégétique à travers leur formation au sein de petits groupes les convertissant en révolutionnaires par le biais de ce rituel éducatif. Ce processus rituel fut d'ailleurs étendu et redupliqué dans les autres bases afin de permettre à ces nouveaux révolutionnaires d'être les bases des programmes d'action dans les villages, les associations d'intérêt national, les écoles d'hiver, les campagnes d'alphabétisation des masses ${ }^{43}$. Pour ceux qui furent diplômés de ces programmes d'éducation supérieure, l'espoir était qu'en utilisant la même méthode de lien exégétique, on supprimerait les barrières de classe et les différences sociales. Aussi demandait-on à chacun d'abandonner son origine sociale, géographique ou culturelle pour se fondre dans 
l'origine révolutionnaire. La discipline résulta donc moins de la hiérarchie que de l'obligation morale. Dans la mesure où bien sûr certains de ces objectifs ne purent jamais être réalisés, la situation conduisit à une hypocrisie généralisée. Les oppositions furent seulement exprimées en privé. Or précisément parce que le lien social était aussi intime, les relations de face à face aussi puissantes, non seulement les personnes ne disaient pas ce qu'elles pensaient mais cherchaient à se le cacher à elles-mêmes. Et lorsque certains personnages très connus comme Din Ling ou Wang Shiwey, critiquèrent publiquement ce qu'ils estimaient mauvais dans le programme, les représailles des hautes instances purent être rapides, brutales et punitives.

La campagne de rectification fut à cet égard orchestrée avec soin. L'exégèse fut organisée comme discours et le discours comme exégèse. A l'intérieur de cette courte période, se déroula une expérience effrayante mais que personne ne pouvait pas ne pas comprendre: la campagne de sauvetage. Cette "campagne de sauvetage" fut initiée sous la direction de Kang Sheng (le "pistolet de Mao", que certains survivants désignent encore comme son "ombre noire") et reposait sur l'idée de sauver les gens de leurs pensées les plus secrètes, et des graves doutes qu'ils avaient peut-être profondément enfouis en eux sans le savoir. Kang Sheng prit le rôle de procureur de cette campagne, et il joua ce rôle en partie déguisé. Il s'habilla de cuir noir, et chevaucha un cheval noir (celui de Mao étant blanc) et il fut toujours suivi par un chien policier noir féroce. Comme agent de Mao dans la campagne de rectification, Kang Sheng symbolisa la cautérisation sociale et intellectuelle nécessaire pour transformer la rectification en purification. Il représenta le Mal nécessaire pour qu'advienne le Bien.

L'idée de la Campagne de sauvetage (sauvant les gens de leurs illusions et de leurs propres mauvaises pensées) introduisit un élément de paranoïa qui caractérisa de plus en plus Mao. Elle représenta l'élément stalinien du Maoisme. Mao était convaincu à l'époque que des espions et des saboteurs avaient infiltré les rangs du parti (membres des escouades $A B$ du Guomindang) et il fut difficile de le dissuader d'y croire alors que Kang Sheng, jouant sciemment sur sa crainte, affirmait que personne n'était innocent, et que tout le monde hébergeait dans son coeur des réserves à l'égard de la révolution. Kang Sheng considérait d'ailleurs cette question comme une question technique et s'ingénia à trouver les moyens de forcer les individus à confesser qu'ils hébergeaient des pensées subversives, à impliquer leurs camarades... Ces techniques n'étaient pas neuves. Kang Sheng les avait appris lors d'un séjour au NKVD en URSS. Bien que la campagne ne dura qu'un peu plus de trois mois, elle affecta pour toujours le caractère du maoisme. Après coup, on se rendra compte qu'elle était l'élément précurseur de la Révolution Culturelle dans laquelle Kang Sheng joua aussi un rôle leader ${ }^{44}$. Mao mit fin de manière expéditive à la campagne de sauvetage en s'en excusant. Mais elle laissa une marque indélébile même parmi ceux-qui s'étaient engagés dans le soutien des principes de Yan'an. Encore et encore, ceux que l'on interviewait, se référaient à cette décision comme le moment décisif majeur de Yan'an. Beaucoup considéraient que la campagne avait été nécessaire. La campagne de sauvetage ne découvrit virtuellement pas de traîtres. Mais les coups, les suicides, les interrogations et pseudo procès montrèrent le côté absolument impitoyable du procédé du lien exégétique. Malgré cet épisode, les gens décrivent encore les jours passés à Yan'an dans des termes similaires à ceux d'une expérience de conversion religieuse ("un désir de partager", "de se surpasser", "d'excitation à découvrir la vérité", etc. ), ou à une prise de possession. La même personne qui décrivait la campagne de sauvetage avec répugnance pouvait se rappeller l'expérience de Yan'an avec une certaine extase rétrospective, dans des termes que 
Bataille et d'autres ont décrit comme de la jouissance, ou que Freud a décrit comme un sentiment "oceanique" 45 .

Yan'an ou la construction de l'Un fusionnel Il serait exagéré de dire qu'avant la campagne de sauvetage on pouvait voir une innocence authentique dans Yan'an, un engagement plus fondé sur un sens de la dévotion et de l'accomplissement personnel que sur une croyance dans la pureté doctrinale. Mais beaucoup employaient ces termes pour décrire les expériences d'une vie collective totalement alternative à celle de la société Chinoise d'alors - société qu'ils caractérisaient comme empoisonnée, dépravée, malade, faible, trompeuse, cruelle, criminelle). Il y avait un réel enthousiasme pour les nouvelles possibilités issues de la guerre victorieuse et de la révolution à bâtir et où le programme à long-terme semblait côtoyer l'immédiat. Cela permit aux gens de croire que cette campagne de rectification était une expérience valable et que la campagne de sauvetage était un mal nécessaire. En même temps, personne ne pouvait ignorer les dangers que la campagne faisait encourir au mouvement depuis ses dirigeants jusqu'à ses ennemis. Pour rester un bon révolutionnaire, on devait admettre, pour le reste de sa vie, que l'on était finalement une figure incarnée dans la passion rédemptrice de Mao l'Odysséen, et que l'on devait partager la morale socratique de ce dernier, en occultant le fait que Mao était par-dessus tout un individu monopolisant le pouvoir coercitif - un individu rusé, manipulateur, et si nécessaire, meurtrier.

L'objet ultime de Yan'an fut d'apporter la "Lumière". Mais une lumière d'un type particulier. Cela commença par une perte totale des catégories d'entendement, des buts, des objectifs, et se transforma en un programme précis de règles. Les sessions d'études furent soigneusement contrôlées. Les enseignants furent remarquablement bien entraînés, le programme fut préparé avec une méticulosité étonnante. Le travail ne consista pas uniquement à analyser des textes mais à apprendre également à écrire, à composer de la musique, à monter un opéra, une pièce de théâtre. Certains de ces principes étaient bien sûr des applications des théories stalinistes de la culture, mais il y eut une volonté consciente d'utiliser le langage et l'imagerie visuelle comme un dispositif de nivellement par le bas pour parvenir à s'élever. Et ceux qui définirent la manière dont ce nivellement par le bas devait être mené furent de fait exemptés de cet apprentissage. Le discours d'égalité fut donc aussi un "discours pouvoir" au sens où l'entend Foucault dans ses analyses sur la prison et la sexualité. L'argumentaire de la ligne de masse assura la prédominance du système commun de références. Plus important encore, les intellectuels durent eux-mêmes s'abaisser aux niveaux inférieurs afin que tous les autres puissent s'élever ${ }^{46}$. La ligne de masse fut donc un ingrédient crucial dans le triomphe de la méthode du lien exégétique ${ }^{47}$. La spontanéité alla de pair avec la manipulation. Les idées fondatrices furent improvisées "sur le coup" mais Mao bien sûr, ne devint pas une figure socratique en une nuit. Au fur et à mesure qu'il développa les méthodes du lien exégétique dans la campagne de rectification il convertit l'expérience en théorie et la théorie en capital symbolique ${ }^{48}$. Ce fut par ce processus qu'il acquit son pouvoir initial et que d'une personne relativement accessible, donnant l'impression d'un homme sociable, habillé avec des vêtements simples ordinaires, renonçant à porter l'insigne et la marque de son rang, il se métamorphosa en un grand cosmocrate. Ce qui distingua les Yan'anites des membres des autres bases frontalières réside dans ce fait que ceux qui rejoignirent la révolution à Yan'an devinrent d'une certain façon le peuple du Livre, c'est à dire le peuple élu de la Révolution chinoise. Ce fut à Yan'an que les commandements du parti et les textes 
exégétiques furent écrits, et ils continuèrent jusqu'à encore récemment à servir de Saintes Ecritures à la révolution ${ }^{49}$.

Que fut ce cosmos? Il fut structuré par l'histoire d'une double perte, perte du patrimoine et déplacement du lieu du pouvoir. Le patrimoine familial du paysan a été abandonné au propriétaire terrien, et le patrimoine national aux étrangers, la perte du second entraînant la perte du premier. Il en résulte une double marginalisation dans un double capitalisme devant être rectifié par la révolution dans le premier cas, et par le nationalisme dans le second. Le corpus prescriptif inclut une épistémologie dialectique, une théorie de la praxis, pour fournir une structure qui permette de récupérer, de racheter ces patrimoines; ce qui a été perdu pouvant être restauré mais seulement dans des conditions qui transforment le patrimoine lui-même. De fait, en prenant possession de leurs patrimoines les marginaux et les dépossédés reprennent possession d'eux-mêmes.

L'effet de simulacre En résumé, Yan'an ne fut pas seulement une base, une redoute, mais le centre symbolique ou la matrice de l'accumulation du capital symbolique. La combinaison de récits et de textes forma une série de trois cercles concentriques correspondant aux récits décrits plus hauts, sorte de mandala Tantrique, avec Mao, équivalent de Bouddha, en son centre. Le premier cercle illustre la chute, avant et après l'effondrement de la dynastie Qing, c'est à dire le chaos originel et l'anarchie qui doivent-être vaincu par un panthéon composé des membres du comité central qui, avec Mao, représente le projet transcendant. Le second cercle décrit la singulière férocité des relations internes, les relations entre le PCC, le bien, et le GMD, le mal. Le troisième cercle décrit les luttes de Mao pour le pouvoir au sein du parti, sauvant ce dernier des corrupteurs de l'intérieur et des séducteurs extérieurs (comprenant aussi bien les trotskistes, que les engeances domestiques). Le prisme central de ces trois cercles concentriques est constitué par l'oeil : Mao lui même. D'où la description faisant de Yan'an une république platonicienne dont la hiérarchie politique s'inscrit et est cachée dans la relation "maître"/"élève" (en dépit de l'égalité présumée) ${ }^{50}$. On peut parler à ce propos d'une sorte "d'accumulation primitive" du "capital symbolique", c'est à dire de la constitution d'un pouvoir à partir des matières premières du langage, des signes et des symboles ${ }^{51}$. Les éléments constituant la cosmologie maoïste furent construits ici sur des métaphores visuelles, dont les événements concrets prenaient la place d'autres événements entrant en résonance les uns avec les autres, et avec des métonymies textuelles. Ces événements étant utilisés comme des représentations des théories de Mao, plus le maoisme domina, plus les querelles (y compris celles provenant de l'URSS) entre les différentes factions du parti s'affaiblirent. L'intervention du Komitern en fut réduite de façon drastique. Et c'est d'ailleurs ce qui est aussi intéressant dans Yan'an. Nous sommes témoins d'un discours à effet performatif de communauté platonicienne placé sous les auspices d'un parti à la tête duquel on trouve un unique agent dialectique ${ }^{52}$. Formant un discours unifié par l'élimination des autres, employant un langage politique parlé par tous d'une seule voix, et aux moyens du processus de lien exégétique, il élimina tous les langages concurrents ou toutes les interprétations alternatives (celle de Wang Ming par exemple). Pour le dire en termes bakhtiniens, le discours lui-même fut réduit d'un état d'hétéroglossie avant la rectification à, après rectification, une "monoglossie", il se transforma en passant d'une synthèse plurielle de croyances à une sorte monisme dans lequel le peuple perdit le désir ou la volonté de parler une autre langue que celle du pouvoir. Néanmoins cette réduction à un discours unifié est enrichie par les métaphores et les récits qui le prolongent à travers un 
discours logique se déployant en trois récits, en trois cercles concentriques. Si cette singularité du discours privilégie l'espace de Yan'an comme lieu de naissance, comme centre du monde, comme la caverne d'où sont nés les premiers micro-organismes, comme la première cité d'Ur, c'est aussi le lieu du simulacre de la future société d'un monde à reconstruire mais qui ne l'est pas encore. Yan'an invertit la perception de l'espace et la construction de la réalité telle que la voit les participants extérieurs. Il révéle la potentialité du monde créé par les participants de l'intérieur, par les initiés. Pourtant sous une telle vision romantique affleure en permanence la poursuite impitoyable du pouvoir. Bien sûr dans ce contexte il fait sens d'affirmer que Yan'an illustre comment l'expérience est transformée en discours, le discours en interprétation, et l'interprétation en théorie, embellie et enseignée jusqu'à devenir le coeur du plus grand corpus existant : les Travaux Choisis de Mao Zedong. Ainsi, on peut considérer que Mao, faiseur de mythe, architecte moral de la révolution est l'interprète principal du drame qu'il écrit, mais qu'il prit le risque grave de ne pas suivre le script jusqu'au bout.

50 Même aujourd'hui, en dépit d'une amertume aux regards des opportunités perdues, ce qui demeure dans les entretiens à propos de Yan'an, ce ne sont pas les épreuves (même si les souvenirs de certaines d'entre elles demeurent suffisamment vives), mais une nostalgie pour la perte de l'unification de la détermination individuelle avec l'action collective. Pour nombre de Yan'anites, même aujourd'hui, chaque acte ordinaire devrait receler une leçon. Yan'an reste donc pour eux un triomphe du principe révolutionnaire, une intentionnalité, une volonté. Ce sont ces caractéristiques, ces qualités, qui ont, pour certains des participants et observateurs, donné à Yan'an son empreinte héroïque, et impressionné des personnes comme Anna Louise Strong, Agnès Smedley, et Edgar Snow. Ce qu'ils ont vu à Yan'an c'était le "peuple élu" vivant dans des cavernes (ce qui symboliquement représente la condition humaine originelle) et pourtant résolu à refaire le monde.

51 La réapparition des différences sous le règne de l'Un En dépit de tous les efforts pour une vie commune et partagée, de réelles différences de perspective demeurèrent. $\mathrm{Si}$ parmi les jeunes instruits et aux idées radicales qui avaient traversé les lignes japonaises on voit qu'ils se souviennent encore de leur vie comme d'une consécration, comme d'une détermination absolue en face d'une épreuve absolue, comme le triomphe de leur volonté révolutionnaire, en revanche un certain nombre, ressentirent cette conformité comme une obligation. Pour d'autres encore le lien exégétique a pu être vécu comme un instant chaleureux, et même comique. Enfin, pour certains commandants de guérilla envoyés à Yan'an après des années de combats, ce fut une pratique inconséquente. L'aspect de Yan'an qui les attira le plus ce fut ce luxe de paix et de tranquillité.

52 Tous, donc, en dépit des apparences ont été déçus. Et si les observateurs extérieurs voyaient dans les dirigeants des personnes remarquablement accessibles, menant une vie presque semblable à celles de leurs partisans, ceux qui se trouvaient à l'intérieur remarquaient que les chefs portaient de meilleurs uniformes, se déplaçaient à cheval (au lieu de marcher à pied), mangeaient une nourriture plus raffinée et plus importante que les autres, et avaient accès aux femmes par des moyens non accessibles au commun des partisans ${ }^{53}$. Pour un intellectuel comme Wang Shivei ceci représenta non seulement une hypocrisie, mais une duplicité de la part des dirigeants, et une immoralité méprisable. Ses critiques persistantes firent véritablement de lui une épine dans le pied 
de la classe dirigeante. Aujourd'hui et spécialement après les événements de la place Tiananmen cet effort gigantesque pour imposer cette Unicité apparaît alors comme une imposture, un canular, une sorte de réalisme magique usant de manipulation linguistique pour obtenir des effets spéciaux ${ }^{54}$.

En dépit de la nouvelle poussée de l'orthodoxie post-Tiananmen, les ambiguités qui prévalaient déjà à l'apogée de Yan'an sont devenues une source d'humour ironique. Aujourd'hui le portrait Yan'an est par certains côtés ridicule. Si l'on souhaite parler de Yan'an avec des Chinois, nombre d'entre eux rejettent la discussion avec un mépris visible pour ceux qui y ont participé. Pour les jeunes Yan'an est inconséquent, il a disparu de l'histoire chinoise. Ce qu'ils en savent est le mythe officiel qu'il faut apprendre à l'école. Questionnés à propos Yan'an certains étudiants riront, d'autres seront embarrassés, d'autres encore vous regarderont étonnés que vous puissiez être intéressé par un tel sujet. Pour les quelques survivants de Yan'an en revanche, l'expérience reste quelque chose de magique, demeurant plus que jamais le moment de pureté de la révolution, quand celle-ci promettait encore une nouvelle vision de la Chine et des chinois. Petit en nombre, ce groupe n'en comprend pas moins certains des vieux qui sont encore au pouvoir, il y a chez eux cette volonté de ne pas abandonner la révolution et de s'y accrocher comme si elle était leur propriété privée. Mais même parmi ces individus, qu'ils soient survivants ou victimes (chacun jouant à une époque donnée un des deux rôles) des querelles entre les factions, des renversements de la ligne du parti, droitiste ou gauchiste, aucun ne conserve une réelle illusion sur la manière d'exercer le pouvoir. Ils peuvent certes compter sur le discours de Yan'an pour légitimer leur exercice du pouvoir mais, dans leur petit cercle, à l'écart de la vue publique, ils savent bien qu'une bonne partie de leurs actions, des conflits et des rivalités qui les opposent aujourd'hui remontent à cette période de Yan'an où ils se divisaient entre membres des première, deuxième ou quatrième Armées dirigées par Mao et Zhang Guotoa. Et tout comme les anciens empereurs de Chine, ils combinent la rudesse de leur pouvoir avec le discours de la vertu.

Les Quatre Luttes Nous abordons maintenant la quatrième partie de cet article qui est aussi la plus phénoménologique. Cette partie traite des conditions historiques dans lesquelles le processus que nous avons décrit a pris naissance. Nous avons vu comment Yan'an fut construit à partir du rôle de Mao. Nous voudrions maintenant montrer comment il a réussi systématiquement à triompher dans les luttes de pouvoir et comment il a réussi à se placer au centre cosmologique de la ligne du parti. Pour ce faire nous décrirons ce que l'on peut considérer comme les quatre rapports de force principaux que Mao rencontra dans sa lutte pour imposer son hégémonie sur le parti et pour imposer l'hégémonie de son discours. Si comme nous l'avons suggéré, Mao se transforma de figure Odysséenne, (leader d'une petite bande cherchant à recouvrer son patrimoine perdu) en une figure socratique, cela ne se fit pas aisément et sans luttes féroces. Il lui fallut monopoliser quatre sortes de formes de pouvoir, dont chacune représente un des points cardinaux du cosmos de la Chine communiste et un minimum irréductible nécessaire à la création d'une communauté utopique. Véritables travaux d'Hercule, où à travers les rapports de force et le spectacle des rivalités, il lui fallut toujours choisir le bon côté. Or, en gagnant les hauteurs du commandement, Mao réussit effectivement à prédominer sur le plan militaire, sur le plan du contrôle central, sur le plan de l'orthodoxie du parti et sur le plan de l'autorité intellectuelle. Chacune de ces dimensions a été personnalisée par une figure s'opposant à Mao: Zhang Guotoa, commandant de la puissante quatrième Armée, Liu Zhidan commandant de Yan'an 
avant l'arrivée de Mao, Wang Ming le représentant du Komintern et le précédent sécrétaire général du parti, Wang Shinwei l'un des rares véritables intellectuels vivant à Yan'an. On doit bien voir que ces luttes nous montrent bien autre chose que les capacités tactiques de Mao, même si bien sûr celles-ci ont joué. Il était important à Yan'an d'être du bon côté faute de quoi on se retrouvait expulsé, torturé, blessé ou mort. Mais être du bon côté, c'était aussi participer à une victoire sur le ciel car ces luttes créaient leur propre réalité. Elles étaient l'occasion pour Mao de créer son "oralité" et sa "textualité" en se différenciant des autres. C'est donc dans le contexte de ces quatre luttes que Mao transforma ses discours et ses textes en principes éducatifs, et transmuta la matière première des expériences individuelles en corpus mythique. Ainsi chacune des luttes est une lutte entre prétendants au pouvoir mais aussi une lutte qui oriente le contenu du discours maoïste. Avec Zhang Guotoa, il ne s'agit pas que du pouvoir militaire mais aussi de la conception du marxisme et d'un choix entre un cosmocratisme ou un ingéniering social. Très concrétement cela joua sur qui contrôlerait le Politburo. Avec Liu Zhidan, il ne s'agit pas simplement d'un conflit sur la nature décentralisée ou non du pouvoir mais sur la définition de qu'est le centre et ce qu'est la périphérie. Avec Wang Ming, cela va au delà de savoir quelle ligne idéologique s'imposerait, celle du Komintern ou celle de Mao, il s'agissait d'une lutte entre l'internationalisme prolétarien et le nationalisme maoïste voulant s'universaliser luimême comme troisième voie. Avec Wang Shiwei, ce n'était pas seulement la question de la monopolisation de la vie intellectuelle qui était en jeu mais le statut même des "vrais" intellectuels comme Lu Xun à l'égard de la révolution et de la société chinoise.

La lutte militaire Dans le conflit l'opposant à Zhang Guotoa, Mao réussit toujours à garder le contrôle sur le Politburo et le programme. Ce faisant il fixa le cadre à l'intérieur duquel zhang Guotoa pouvait manoeuvrer. Il put le faire en partie en utilisant le "miracle" constitué par la Longue Marche et la survie de ses troupes, comme une illustration du succès de ses principes tactiques et stratégiques. En élargissant ces principes à un système de règles appropriées, il délimita la ligne séparatrice entre la stratégie militaire permise et la stratégie militaire interdite. Dès lors, en dépit du fait que Zhang Guotoa, avait à sa disposition une force militaire plus importante que celle de Mao, il fut à la fois séduit par Mao, n'osa le défier sur le terrain et vit ses intentions déjouées. Comme Mao, membre fondateur du Parti communiste chinois, et pendant longtemps plus éminent politiquement que ce dernier, Zhang a de son propre fait conduit le front de la quatrième armée dans une longue marche vers Sichuan bien avant que Mao ne se lance lui-même dans sa marche (c'est à dire durant la quatrième et non la cinquième campagne d'extermination). A Sichuan, Zhang établit une base précaire (dans une zone où la consommation d'opium était considérable et l'objet d'une grande préoccupation). Son armée épuisée, sa direction divisée, Zhang n'était pas disposé à suivre les instructions relatives à la conduite des affaires provenant du Comité Central. Lentement et grâce à une gestion très habile, à partir de 1933, la quatrième armée se renforça constamment en remportant une série de batailles locales. Par ailleurs, les politiques administratives et les réformes qu'il entreprit furent beaucoup moins profondes et radicales que celles prônées par le Comité Central. Zhang Guotoa résista par exemple aux instructions du CC au motif que les gens préféraient un dégrèvement fiscal et étaient ravis par les succès militaires de son armée, mais qu'ils ne voudraient pas d'une vaste de redistribution des terres ni d'une élimination de masse des propriétaires terriens ${ }^{55}$. En 1935, les forces de Zhang Guotoa traversèrent la rivière Chia-ling sous le feu de l'ennemi pour faire la jonction avec la première armée de Mao. 
Zhang fut favorable immédiatement à la constitution d'une fédération Nord-ouest. Il rencontra à ce moment là Mao, qui était déjà en lutte avec Wang Ming, le représentant du Komintern qui avait remplacé Li Li San à la tête du parti. Mao venait juste d'apparaître lors de la conférence de Zunyi comme un chef de premier ordre. Mais sa position était encore précaire et il ne savait pas encore où la Longue Marche allait se terminer. La réunion ne fit donc qu'accentuer la suspicion que Mao nourrissait à l'égard de Zhang. Mao se refusa à l'idée qu'il existât une fédération Nord-ouest car il pensait que prendre en considération la supériorité de la quatrième armée revenait en définitive à chercher une excuse pour le remplacer par Zhang Guotoa. L'histoire de leur conflit a été écrite et réécrite à maintes reprises et nous n'avons pas l'intention ici de rentrer dans les détails. Cependant une chose apparaît de façon très claire. Il ne s'agissait pas seulement de deux hommes à la personnalité complètement opposée, en effet Zhang n'avait pas une très grande considération pour les qualités de Mao, ni en tant que stratège militaire ni en tant que chef. De son propre aveu, Zhang considérait Mao comme un imaginatif et un sensible. Ses réflexions devenaient parfois bizarres, il voulait fabriquer des propos mythiques. Il manquait d'habileté pour organiser, et hésitait à établir des calculs précis quand il était confronté à des questions difficiles. Parfois, ses idées n'étaient pas clairement exprimées et souvent il présentait ses "opinions de génie" sur un mode émotionnel ${ }^{56}$. Mais il sous-estima les capacités de Mao et l'apprit à ses dépends. Après la réunion Mao Er Gai du 20 août, Mao décida de changer la direction de l'Armée Rouge et d'aller vers le Nord Est. Zhang refusa de suivre. Il soutint que la rivière était devenue infranchissable à cause de pluies torrentielles. Il soutint que l'unité armée protégeant le Comité Central ne devait pas partir. Bien que Zhou Enlai, Zhang Wentian, Bo Gu, Mao, Xu Xiangqian, Chen Changhao, et Wang Jiaxiang lui aient envoyé un télégramme lui demandant d'aller au Nord et non au Sud, le 9 septembre Zhang envoya trois télégrammes. Un premier aux généraux de l'aile gauche de l'Armée de terre déclarant "notre but est d'aller au Sud". Un deuxième à Cheng Changhao lui ordonnant de conduire ses troupes vers le Sud et de "se lancer complètement dans la lutte interne du parti". Enfin un troisième fut envoyé au Comité central, lui expliquant que le plan qui consistait à aller vers le Nord présentait des difficultés et il suggéra fortement de renoncer au plan de bataille initial de Xuia Tao. Le jour suivant Mao au sens littéral du terme échappa à Zhang en allant vers le Nord, prenant avec lui la première et la troisième armée et laissant derrière lui la quatrième armée qui sous les ordres de Zhang commençait à marcher vers le sud. Le Comité central, indigné, exigea alors que la totalité de l'Armée rouge se dirige vers le Nord. Le 12 septembre un plénum élargi du Politburo se réunit à $\mathrm{E} J i e$, (Gansu) pour critiquer Zhang. Celui-ci, en réponse, rompit avec la discipline du parti et, ignorant l'autorité du comité central, établit son propre comité central provisoire avec lui comme secrétaire ${ }^{57}$. Il s'ensuivit de longues et complexes séries de manoeuvres, débouchant en fin de compte sur un rapprochement très limité. Le Comité central légitime établit un Bureau Nord-Ouest faisant de Zhang Guotoa son secrétaire et de Ren Bishi son vicesecrétaire. Après une période prolongée de tractations concernant la proposition de plan de bataille de Ningxia, Zhang fut amené, plutôt contre sa volonté d'ailleurs, à diviser ses forces. Lors de la bataille qui suivit, une partie de son armée fut défaite. Après cela il ne constitua plus longtemps une menace pour Mao.

56 La question qui reste à éclaircir est cependant de savoir pourquoi Zhang recula et accepta en définitive (à contrecoeur cependant) l'autorité du Comité central après avoir défié les règles du parti en voulant constituer un comité alternatif. Pire, il avait 
même envoyé un télégramme encourageant le renversement de Mao et pourtant, il revint discuter avec lui en dépit du fait qu'il avait une puissance militaire supérieure sur le terrain à celle de Mao et accepta les plans de ce dernier conduisant à la destruction de la quatrième armée. Mao fut donc capable durant cet épisode de rappeler à l'ordre Zhang, non par la force, mais par une combinaison de force logique et d'appel à la vanité. Mao avait bien compris qu'un conflit entre eux pouvait se solder par leurs disparitions mutuelles. D'où leur réconciliation, au moins sur le point qu'il fallait accepter les règles du jeu et l'absence de condamnation immédiate de Zhang pour sa création d'un comité central alternatif. Mais avec Mao maintenu aux commandes du Comité Central, c'était une situation à somme nulle. (en effet non seulement Mao conserva le soutien du Comité Central en dépit de la sympathie de Zhu De pour Zhang) et Mao ne perdit plus jamais le pouvoir de définir la portée des options réalisables. Zhang tenta bien désespérément de conserver intact le pouvoir de la quatrième armée et l'autonomie d'établir sa propre base. Mais Mao avait désespérément besoin de diviser la quatrième armée, de diviser son commandement, et d'empêcher que le "grand schisme" entre lui et Zhang ne devienne effectif. Zhang proposa en premier une stratégie conjointe, une force unie pour vaincre le GMD et établir une base unifiée. Mao s'y opposa car en cas d'attaque avec une force unifiée, si cette dernière perdait, tout serait perdu. Il proposa donc une attaque divisée dans laquelle la quatrième armée, parce que la plus forte, supporterait le plus fort de l'attaque. C'était pour Zhang un pari intéressant. S'il gagnait contre le GMD il pouvait établir une base élargie dans le nord du pays et avoir un lien direct avec l'URSS. Cependant s'il perdait, la première et la seconde armée du PCC seraient, elles, intactes face à son armée affaiblie. Or ce risque là était inacceptable. Zhang Guotoa proposa donc qu'aucune bataille n'ait lieu et que ses forces se dirigent vers le Sud comme il l'avait dit et ensuite vers le Nord-Est. Mais cette option fut écartée par le Comité Central. Si Zhang agissait à nouveau à l'encontre de cette décision, il violait les règles une seconde fois, situation qu'il considéra comme fatale. Ainsi, le "jeu" joué par Mao fut par dessus tout un jeu de pouvoir et de légitimité. Mao avait une forte légitimité politique et un faible pouvoir militaire. Zhang avait un pouvoir militaire fort et une légitimité politique faible; (Zhang était en outre très vaniteux). Il accepta le poste de secrétaire du bureau Nord-Ouest parce qu'il lui procurait une position de grand prestige. Et ensuite il décida de tenter sa chance sur le plan politique, où malgré la division de son Armée, il pensa pouvoir gagner le contrôle du Comité Central, lui donnant cette fois la légitimité nécessaire pour défier Mao. Ce fut une décision erronnée qui permit le massacre d'une partie de la quatrième armée durant les deux mois de la bataille de Ningxia. Malgré cela Mao ne put "achever" complètement Zhang que beaucoup plus tard. Le 17 avril 1938, Mao put obtenir l'expulsion de Zhang Guotoa du parti par une résolution du Comité Central l'accusant d'activités trotskistes ; peu de temps après Zhang rejoignit le Guomindang.

57 Le centre contre la périphérie Le second cas demeure un mystère. Liu Zhidan a toujours été l'un des héros de la révolution. Snow le décrit comme une figure exemplaire, comme un partisan rouge, moitié bandit moitié militant communiste, que l'on retrouve partout dans Shaanxi, promouvant la réforme agraire, exécutant les propriétaires fonciers, exerçant une attraction sur ses partisans qui le suivait avec dévotion. Ce fut plutôt le chef d'une bande de partisans indisciplinés, brouillé avec les autorités centrales du parti. Snow raconte comment une vague figure du parti surnommée "Chang le corpulent" inventa des charges contre lui, et qu'à la suite du conflit fratricide 
au sein du parti il fut emprisonné et nombre de ses disciples torturés et tués ${ }^{58}$. Il décrit d'autre part comment Mao l'a libéré, et comment il mourut "en regardant les collines qu'il avait parcouru et aimé quand il était jeune garçon, vivant parmi les montagnards qu'il avait conduit tout au long de cette route à laquelle il croyait, la route de la lutte révolutionnaire. Selon d'autres sources, Liu Zhidan tel un chef partisan local, diplômé de Whampoa se heurta en premier avec les partisans de la ligne défendue par Wang Ming. C'était avant l'arrivée de Mao au pouvoir. Il n'appréciait pas Wang Ming, et n'avait pas l'intention d'accepter qu'on lui indique ce qu'il fallait faire du "sommet de la montagne. Il lança ainsi un défi au parti en revendiquant l'indépendance locale face au contrôle central. Deux "émissaires" politiques furent alors envoyés de Shanghaï pour discuter avec lui, Zhu Lizhi et Guo Hongtao. Ils prétendirent représenter le Comité Central, mais Liu émit des doutes sur leurs accréditations, remarquant que le Comité Central effectuait la Longue Marche et qu'il n'était donc pas à Shanghaï. Il leur demanda s'ils avaient des preuves d'avoir consulté le Comité. Comme Zhu Lizhi et Guo Hongtao ne disposaient d'aucun pouvoir militaire propre, on en resta là. Mais Xu Haidong et sa vingt-cinquième armée arriva entre temps à Shanbei. Ancien "bandit" lui-même Xu Haidong (le "potier rouge" selon Snow) était aussi un partisan de Wang Ming. Son commissaire politique était Chang Zihua, réputé pour avoir massacré de nombreux communistes à la base de $\mathrm{E} Y u$ Wan. C'était à la suite des excès de Cheng que l'armée de Xu avait été obligée de quitter la base pour se diriger vers le Sud. Cette campagne se traduisit par l'assassinat inconsidéré des membres du parti (il fut dit qu'il avait pris au piège un important chef d'une brigade communiste, Zhang Hanmi qui, sous les ordres du général Yang Hucheng, était chargé du parti communiste clandestin dans le Sud Shaanxi, et qu'il l'avait fait bouillir). A son arrivée à Shanbei Xu et Cheng joignirent leurs forces à Zhu Lizhi et Guo Hongta. Xu Haidong voulait allier les effectifs de sa vingt-cinquième armée, la vingt-sixième armée rouge et la vingt-septième armée rouge de Liu Zhidan pour qu'elles forment le quinzième groupe armé ${ }^{59}$. Il forma un "groupe de délégation central" ( qui était supposé s'être constitué sous les auspices du Comité Central) et commença à modifier l'organisation du parti afin d'en obtenir le contrôle. Sa principale cible était la Commission militaire Nord-ouest, dont le Comité de la ligne de Front avait eu Liu comme directeur général. Bien que Xu ait atteint à son but, Liu Zhidan grâce à son habileté en tant que commandant militaire devint le chef d'Etat major. Lors de la bataille de Laoshan, contre les troupes de Zhang Xueliang (le "jeune shérif"), où Liu Zhidan était commandant, 3000 combattants ennemis furent faits prisonniers. Ce fut un triomphe personnel pour Liu Zhidan. Mais presque immédiatement un mandat d'arrêt à son encontre fut diffusé, ainsi qu'à l'encontre de ses chefs militaires de plus haut rang. La campagne d'élimination des contrerévolutionnaires avait été lancée. Bien qu'il eut connaissance de l'existence du mandat d'arrêt le concernant et malgré l'incontestable supériorité des forces militaires qui lui étaient fidèles, il n'a pas essayé de s'échapper, au contraire il a lui-même permis son arrestation ${ }^{60}$. Durant son emprisonnement il fut torturé. Mais Liu Zhidan n'a jamais cédé. En dépit de la campagne "Confessez vos crimes", il persista à dire qu'il n'avait commis aucune erreur. Il fit remarquer à ceux qui le retenaient prisonnier qu'il aurait pu les détruire mais qu'il avait la ferme conviction que la base était plus importante que ceux qui la contrôlaient. ce qui exaspérait Xu Haidong. Certains partisans de Liu furent enterrés vivants. Le secrétaire du comté, Du Wan fut jeté dans un trou, et enterré jusqu'à la poitrine. Sa tête devint violette et son nez commença à saigner. Il supplia ses bourreaux de le tuer mais ils n'en firent rien. Il finit par suffoquer et 
mourut. Il y eut beaucoup d'autres atrocités. Un membre de la famille de Liu Zhidan alla voir Yang Shangkun et Mao, et leur dit ce qui s'était passé. Zhou Enlai en fut aussi informé. Zhou qui avait connu Liu du temps de Whampoa demanda immédiatement sa libération de prison qu'il obtint. Liu avait été promu vice directeur de l'office du Nordouest sous Zhou Enlai lui-même. Mais contrairement à son vieil associé, Gao Gang, Liu continua à défendre le principe d'une autonomie locale et ne fut pas plus disposé à se soumettre à Mao qu'il ne l'avait fait vis à vis de Wang Ming. Trop éminent pour être révoqué, trop célèbre pour être ignoré, trop bon commandant militaire pour être employé en tant que cadre administratif, Mao le plaça à la tête des forces de l'armée rouge lors d'une bataille au cours de laquelle on dit qu'il fut pris sous le feu d'une mitrailleuse tirant d'un mirador. On ne sait pas encore exactement s'il fut sacrifié par le PCC ou tué par le GMD. Sur son dossier il fut qualifié de "Droitiste sérieux".

Le Komintern contre le marxisme sinisé Nous pouvons seulement aborder brièvement les deux derniers cas. La véritable histoire de Wang Ming reste à faire. Sa propre version du conflit qui l'opposa à Mao (et dans laquelle il affirme que Mao l'avait empoisonné) fut publiée à Moscou où il s'était enfui et où il finit par mourir ${ }^{61}$. On a dit que Wang Ming était un marxiste bien supérieur à Mao. Ancien étudiant de l'université de Sun Yat Sen à Moscou et chef de ceux qu'on appelaient les "vingt huit bolcheviques et demi " qui furent formés sous les ordres de Pavel Mif en URSS, il remplaça Li Li San au poste de secrétaire général du parti à 29 ans. et resta au pouvoir de 1931 à 1935. Pendant la Longue Marche, il fut, à Moscou, le représentant chinois du Komintern et le favori de Staline. Au septième Congrès du Komintern il fit l'un des principaux discours (relatif aux mouvements révolutionnaires dans les pays coloniaux et semi coloniaux), fut élu au présidium du Comité exécutif, et fut choisi comme l'un des trois candidats au secrétariat des sept hommes ${ }^{62}$. Ce fut lors de cette réunion que le principe d'un front uni contre les Japonais fut lancé par Staline, renforçant une querelle, qui remontait avant 1927, sur la façon dont le PCC pouvait coopérer avec le GMD dans son combat contre les Japonais. Depuis le début, l'attitude de Mao avait été de s'associer avec le GMD tout en gardant intacte l'autonomie et la structure du parti, attitude qui ne coïncidait pas exactement avec celle de Staline. De retour en Chine, arrivant à Yan'an en 1937 avec Kang Sheng et Chen Yun dans les turbulences liées aux suites de l'incident de Xian, Wang Ming voulut redéfinir la ligne du parti. Il rejeta "l'aventurisme" de Li Li San dont les choix tactiques militaires avaient été tenus pour responsables de la mort inutile de nombreux chefs communistes de haut rang, et qui couplés à la notion de guerre paysanne et des méthodes de guérilla de Mao, avaient entraîné la destruction presque totale du PCC. De plus, il s'opposa aux principes de la révolution paysanne tels qu'ils avaient été lancés par Mao dès les premiers jours de la progression dans le Hunan. En outre, Wang Ming fit preuve dans le débat d'une connaissance et d'une aisance avec les principes du marxisme nettement supérieures à celle de Mao (c'était d'ailleurs le cas de la plupart des autres vingt huit bolcheviques et demi ). Plus orthodoxe au sens stalinien du terme, il croyait que le fait de ne pas considérer le prolétariat comme la force conductrice de la révolution avec la paysannerie mobilisée derrière, revenait à laisser échapper la force motrice essentielle de la révolution. Ainsi malgré son opposition à Li Li San il appuya la stratégie de Moscou centrée sur le prolétariat urbain et la reconquête des villes ${ }^{63}$. Il favorisa également la version staliniste du Front Uni avec le GMD contre le Japon, soutenant que "la principale faiblesse et insuffisance de notre parti reste la même ; premièrement, nous n'avons pas compris que la politique du Front Uni est la principale arme tactique et la seule que 
nous puissions utiliser pour mettre en pratique notre slogan pour une guerre révolutionnaire nationale. Deuxièmement, nous n'avons pas encore réussi à relier nos tactiques de front uni anti-impéraliste à nos activités dans d'autres sphères". Il préconisa de mener des politiques de confiscation limitées en respectant les koulaks, les artisans, les propriétaires terriens sympathisants de la guerre contre les Japonais. Cela supposait d'abandonner le contrôle par les travailleurs des entreprises industrielles et de permettre à des non communistes de combattre dans l'Armée Rouge. Wang Ming favorisa aussi l'association étroite avec Chiang Kai Shek (comme l'avait fait Zhang Ghotoa), et laissa sous-entendre que Mao représentait un élément sectaire du parti ${ }^{64}$. Mao s'opposa bien évidemment à Wang Ming, adoptant certes quelques uns de ses points de vue concernant les questions relatives aux confiscations et aux propriétaires terriens, etc., mais sans transiger cependant sur ses positions fondamentales à l'égard de l'autonomie et la primauté de la révolution au sein de la guerre anti-japonaise. Il joua, au début, au jeu du chat et de la souris avec Wang Ming sans l'attaquer directement mais il allait plus tard finir par l'humilier. La raison ostensible du lancement en 1943 de la Campagne de Rectification réside justement dans la volonté de Mao de répudier la ligne défendue par Wang Ming et de briser le pouvoir des vingt huit bolcheviques et demi. Ce fut surtout une excuse pour éliminer Wang Ming. Le groupe des vint huit et demie était non seulement partagé quant à la doctrine à suivre, mais l'un des principaux : Kang Sheng s'il constituait certes dans la pratique une figure du stalinisme évidente. était aussi l'un des plus anti-stalinistes. Avant même le retour de Wang Ming d'URSS en Chine, l'influence du Komintern au sein des conseils de décision du Politburo avait diminué. L'influence de Li Da (Otto Braun) avait été brisée. Et Staline fut traité avec à peine plus de prudence. Wang Ming ne l'avait pas compris et ses attaques contre Mao échouérent. Mao put même se permettre de le conserver à ses côtés. On peut dire que Wang Ming devint le bras droit de Mao en rentrant et n'eut pas les possibilités de le concurrencer sérieusement. Bien sûr il fallait toujours pour Mao tenir compte du soutien de Moscou. Et Wang Ming lui-même fut peut-être plus populaire en Chine que ne le suggèrent les auteurs contemporains. Il fut, après tout, l'autorité la plus élevée du Komintern pour les affaires coloniales. En outre, l'on dit qu'il revint en Chine en partie pour négocier directement avec Chiang Kai Shek, sur ordre de Staline. Mais il devint rapidement évident, qu'il s'était autorisé lui-même à parler au nom du Parti (et de Staline) sans l'autorisation du Comité central. Son influence diminua alors très fortement et de plus il tomba malade. Vers la fin méprisé et relégué à des postes mineurs, il rentra finalement à Moscou ${ }^{65}$.

La lutte intellectuelle Le dernier cas de lutte empêchant Mao d'arriver immédiatement à monopoliser le pouvoir a été récemment exhumé grâce essentiellement aux efforts d'une remarquable journaliste, Dai Qing. Le cas Wang Shivei représente, pour nombre de personnes, la personnification de l'utilisation et de l'utilisation abusive des intellectuels par Mao. Il a suscité un intérêt considérable chez les spécialistes américains et français de la Chine ${ }^{66}$. Il constitue un bon exemple des multiples éléments à analyser sur la lutte pour la constitution du capital symbolique qui nous intéresse dans cet article. Il nous renseigne sur la façon dont l'un des rares "véritables" intellectuels (plus connu en tant que traducteur) devint un symbole de résistance à la définition de Mao du rôle des intellectuels et au delà à la volonté de Mao d'unifier le sens de la Révolution.

Pour Mao le rôle des intellectuels était d'être subordonné à la révolution comme il l'avait dit au "forum de Yan'an sur les arts et la littérature". Rejetant vigoureusement 
cette subordination, Wang Shivei devint une sorte de héros de la résistance des intellectuels aux prétentions de Mao. Représentant les intellectuels qui se voulaient de la tradition de Lu Xun (il fut l'un des rares parmi ceux-ci à aller à Yan'an plutôt qu'à Chungking et Yunnan), ses activités coïncidèrent avec la phase préliminaire de la purification idéologique, de 1939 à 1941, et se prolongèrent à la première phase de la campagne de rectification.

61 Cette dernière, nous l'avons vu, commença le 1er février 1942 par un discours de Mao ("Rectifier les trois méthodes") et culmina le 23 juin 1942 par une réunion anti WangShiwei. Cette période fut connue sous l'appellation "exposez vos pensées" ou "la phase de révélation". Mettant l'accent sur la franchise, encourageant les affiches murales et le parler audacieux, elle se traduisit (comme celle des "cent fleurs" une décennie plus tard) par un renforcement du contrôle. Pour Kang Sheng, proche de Mao, le semi-coeur et le double "coeur" (c'est à dire respectivement, le manque de ferveur révolutionnaire et les sentiments anti-révolutionnaires) devaient être soudainement dévoilés par la Campagne. Il prit des mesures contre les deux types d'apostats désigner ainsi et y inclut les espions, les ennemis et les trotskistes.

Travaillant essentiellement à Shanghai, Wang avait rejoint le parti en 1926. Il se lia avec quelques membres de l'opposition trotskiste, et traduisit quelques écrits de Trotsky, ce qui contribua à donner plus de plausibilité à son accusation ultérieure d'être trotskiste (accusation dont le Comité central a maintenant admis qu'elle n'était pas fondée). Il alla en 1936 à Yan'an pour devenir officier de recherche, en fait traducteur, à l'Académie marxiste-léniniste (qui devint par la suite l'Institut central de recherche où Wang se brouilla avec Chen Boda (secrétaire personnel de Mao) lors d'une dispute sur la nature et le contenu de la littérature révolutionnaire). Vu l'importance que donnait Mao aux textes littéraires, il toucha là à un point extrêmement sensible. De plus cette dispute évoquait un ancien conflit entre Mao et le grand écrivain moderne de la Chine, Lu Xun. Parmi les intellectuels radicaux représentant le mouvement du 4 mai, Lu Xun était celui qui attirait le plus l'attention et constituait aussi une source d'inspiration pour les "vrais" intellectuels. Il n'a jamais nourri de sympathie face à la discipline que le parti voulait imposer aux intellectuels. A Shanghai, où il vivait, il entra en conflit avec le tsar culturel du parti local du parti communiste chinois, Zhou Yang. En effet, dans un article qu'il écrivit à Shanghai, Lu Xun dépeignait Zhou Yang comme un dandy, un fat, un homme vaniteux, qui aimait les voitures de luxe, et comme un ignorant dans les domaines de la culture et de la littérature. Zhou attaqua Lu (qui à cette époque connaissait de graves problèmes de santé), le faisant expulser de l'Association des écrivains de l'aile gauche que Lu lui-même avait fondée. Lu Xun mourut peu après, et Zhou Yang se rendit à Yan'an. Mao créa une académie pour les artistes et les écrivains, après la disparition de Lu Xun et nomma Zhou Yang comme directeur. Ce ne fut pas sans conséquence pour Wang Shivei.

Wang fut connu à Yan'an comme un des "quatre excentriques". Dissident depuis le début, il s'associa avec Ding Ling et Liu Xue Wei, tous les deux responsables de la rubrique "art" du journal Quotidien Libération. Peu après le début de la Campagne de Rectification en février 1942, le 9 mars, Ding Ling publia son fameux article "Pensées sur le 8 mars, journée des femmes", lequel attaquait le parti pour la manière dont il traitait les femmes. Mao fut énervé par cet article. Quelques jours plus tard Ding Ling fut démissionnée de son poste de directrice de la rubrique art. Et quelques jours seulement après la démission forcée de Ding Ling, Wang Shiwei publia alors "Les lys 
sauvages". Son article fit l'effet d'une bombe. Publié en deux parties les 13 et 23 mars dans le Quotidien Libération il s'inspirait (selon Cheek) de l'essai satirique de Lu Xun "La rose sans fleurs"67. Critiquant au passage l'attirance de Mao pour les jolies femmes, il offrit comme alternative au modèle exemplaire de femme révolutionnaire dépeint par Mao : Jiang Qing exécutée en 1928. Wang s'attaqua aussi aux soirées dansantes et aux soirées du leader dont la réputation commençait à être fameuse et pour le moins éloignée du modèle révolutionnaire. Il parodia en plus habilement le style de Mao. Il sous-entendit que les trois classes d'habillement et les cinq classes de nourriture qui différenciaient les personnes de rangs différents constituaient en fait un privilège injustifié, véritable privilège de classe, accusation qui mit Mao hors de lui. S'inscrivant dans ce contexte d'autres critiques de la politique du parti dans Yan'an se firent jour à la suite de l'article "Lys sauvages" qui symbolisa la rébellion des intellectuels. Liu Xue Wei critiqua par exemple dans un article publié en juin 1942 la littérature révolutionnaire, la traitant de grossière, stupide, directe, d'inférieure, et insistant sur la nécessité d'un niveau artistique plus élevé. Cet article fut suivi d'un autre article, le 7 juin, réclamant la liberté de pensée comme base de la Nouvelle Démocratie. Le 22 septembre un troisième article affirma que l'accent trop important mis sur la politique affaiblissait le développement des arts. Mais c'est Wang qui fut le plus connu. Wang évoqua sans arrêt l'esprit de Lu Xun pour s'opposer à Mao, suscitant un grand intérêt chez une partie des cadres supérieurs du parti. Wang, devenu une sorte de héros local, participa à la première phase de la campagne de rectification, mais en encourageant nombre de personnes durant cette période à coller des affiches murales dissidentes. Aussi le parti s'alarma-t-il et proposa-t-il l'établissement d'un Comité d'Examen de la Campagne de Rectification pour contrôler les affiches murales. Wang, qui à cette époque avait 36 ans, s'opposa vigoureusement à l'instauration d'un tel comité. Quand il fut clair, qu'un comité serait établi, il insista pour qu'au moins ses membres soient élus, ainsi que les directeurs de tous les départements et le président de l'Académie centrale de la recherche. Il proposa également que les auteurs d'affiches restent anonymes afin de protéger les droits de l'auteur. Les propositions de Wang furent largement soutenues. Toutefois, lorsque les élections se déroulèrent, ceux qui furent élus n'étaient pas favorables à Wang Shivei et à son groupe qui se félicita malgré tout de ce "triomphe de la démocratie". Wang continua à écrire des articles attaquant Lo Mai, le directeur de l'Académie. Il commença une série de journaux muraux appelée "Flêche et cible". Quand certains de ses articles furent imprimés sur du tissu et accrochés à la porte sud de la ville de Yan'an, les lecteurs s'attroupèrent pour les lire comme s'ils se trouvaient en face d'une beauté divine. Wang Shivei devint une star à Yan'an ${ }^{68}$. Le parti ne tarda pas à réagir. Le 27 mai 1942 la "session de lutte" avec Wang Shiwei commença. Parmi les accusations retenues contre lui figuraient celles concernant ses relations avec les trotskistes. Il fut accusé également d'avoir critiqué la nature peu aimable de Staline, d'avoir dit de Karl Radek (qui était accusé de l'assassinat de Kirov) qu'il était une personne estimable. Plus stupéfiant encore, Wang Shivei aurait accusé le Komintern lui-même d'être responsable de la faillite de la révolution chinoise de 1927, et aurait considéré que le procès de Zinoviev et son accusation de traîtrise devait être considérés avec réserve. Il aurait même dit que certaines parties de la théorie de Trotsky étaient pertinentes. Wang fut également accusé de diffamation à l'encontre des dirigeants du parti pour les avoir qualifiés de corrompus, d'avoir brisé l'unité du parti, d'avoir utilisé le terme de "braves" en parlant de ses amis et de "lâches" en parlant des autres camarades. Enfin, ses articles furent considérés comme portant atteinte au Parti et on 
attaqua la manière dont, se prétendant un Lu Xun moderne, il avait appelé la jeunesse à venir lui serrer la main. Les résultats de ces attaques furent partagés. Nombreux furent ceux qui se placèrent du côté de Wang Shivei. Pour éviter la confusion, chacun fut invité par le comité siégeant à lire "l'organisation du parti et la littérature" de Lénine, le discours de $\mathrm{Lu}$ Xun prononcé lors du congrès organisé pour la création de l'association des écrivains de l'aile gauche, les conclusions de Mao au forum de Yan'an sur la littérature et les arts, le premier paragraphe du dixième chapitre de l'histoire du parti communiste et des sélections du second volume des oeuvres choisies de Staline (relatives à l'écrasement des cliques de l'opposition). Wang tenta de démissionner du parti. Sa demande fut refusée. Dans son témoignage fait ultérieurement il revint sur sa décision, mais refusa d'admettre ses erreurs. Kang Sheng, Chen Boda et d'autres le vilipendèrent, lui reprochant son "immonde caractère" et développant leurs propos à travers une série d'exemples qu'ils voulaient détaillés. Finalement tous les membres de l'Institut central de recherche demandèrent son expulsion du parti. Le 11 juin, dernier jour du procès, Ding Ling revint sur ce qu'elle avait dit dans son article du 8 mars, et accusa aussi Wang d'avoir insulté le "cercle des arts et de la littérature". Wang fut emprisonné mais Mao ne souhaitait pas qu'il soit tué. Il voulut l'utiliser comme modèle négatif durant la campagne de rectification pendant qu'il construisait la "voie de Yan'an". En dépit des ordres explicites de Mao stipulant ne pas tuer Wang Shivei (affaibli et malade dans sa prison), quant Yan'an fut attaqué par les forces nationalistes en 1947, Xu Haidong (ou He Long, il y a une incertitude à ce propos) le fit exécuter.

Esquisse d'une théorie de la praxis Ces quatre cas de luttes définissent le contexte immédiat de la politique de Mao à Yan'an. Le premier est le fruit d'un calcul rationnel, d'un pur jeu de pouvoir dans le cadre du mythe du passé et de sa logique projective. Le second porte sur la structure du pouvoir,le définit comme s'exerçant de haut en bas, et non de bas en haut, en dépit de l'illusion démocratique. Le troisième porte sur la question de savoir quel marxisme devait prévaloir et quels textes devaient devenir hégémoniques. Conduit à travers la campagne de rectification, et au fondement du lien exégétique, il instaure l'orthodoxie de la Pensée Mao Zédong. Quant au quatrième, il établit Mao comme seul propriétaire intellectuel du marxisme. Les deux premiers se sont traduits par la mort, les deux autres respectivement par l'exil, et par l'ignominie. Les quatre concurrents de Mao tracent les limites du pouvoir de ce dernier, en définissant par leur résistance, les principes alternatifs refusés par Mao. Ils créent ainsi ensemble un espace assorti de frontières au sein duquel Mao émerge à la fois comme figure militaire suprême et comme cosmocrate. Ses écrits, réédités dans un recueil désigné maintenant sous le nom de Pensée Mao Zédong, universalisa ce qui au départ avait constitué des lectures spécifiques d'événements particuliers. Ils permirent à Mao de se situer entre la ligne droitiste, anti-théorique ou "pragmatique" de Zhang Guotoa et la ligne plus orthodoxe, staliniste de Wang Ming; entre la volonté de décentralisation de Liu Zhidan et le contrôle central étroit prôné par Li Li San, et intellectuellement de se situer contre l'élitisme et le démocratisme de Wang Shivei. Quant au discours, il reconnut lui-même l'importance cruciale de la culture, du texte, de l'écriture, de la littérature et des arts, comme armes de la théorie et de la pratique révolutionnaire. Yan'an a constitué dans le contexte de ces querelles, de ces conflits, mais également dans le cadre d'autres controverses, d'autres luttes, un "espace de mobilisation" ou un "espace sémiotique". Servant de simulacre de révolution, son capital symbolique eut un rayonnement auprès des bases de la guérilla communistes ainsi qu'auprès d'autres bases, telle une version en miniature de la révolution à venir. 
Nombre d'aspects restent d'ailleurs à discuter sur ce rayonnement. Dans son conflit avec Zhang Guotoa et Liu Zhidan, Mao joua un rôle odysséen rejetant les concurrents pour l'obtention du privilège de détenteur de ce patrimoine. Il tint un rôle plus socratique dans ses conflits avec Wang Ming et Wang Shivei, celui d'un dialecticien suprême, d'un cosmocrate, présidant l'histoire tout en la faisant. Ainsi, telles les sorcières de la démonologie de la révolution puritaine, Zhang Guotoa, Liu Zhidan, Wang Ming et Wang Shivei devinrent les "démons" de Yan'an. Chacun représenta une alternative déchue. Avec le renforcement de la Pensée Mao Zedong dans le discours, qu'il existe une manière de penser, un mode de vérité alternatifs fut considérée comme impossible. Comme il ne pouvait exister un point de vue différent ou une vérité alternative, cela signifiait que ces alternatives étaient des alternatives à la vérité ellemême. Un espace s'était constitué entre les doctrines déchues et la vérité dialectique de la Pensée Mao Zédong. La campagne de rectification s'inséra dans cet espace, avec pour conséquence, la formation d'un capital symbolique comme pré-orthodoxie, d'un lien exégétique comme une herméneutique hégémonique, et le corpus lui-même comme norme disciplinaire. De plus, la combinaison de principes articulés et de la lutte impitoyable, fait elle-même partie du processus de narration des récits et de l'expérience interprétative. Or apparaissant très tôt dans Yan'an, chaque lutte laisse un sentiment de doute latent et de contestation potentielle en dépit de la victoire. Aussi, même si cela s'est effectué de manière inégale, particulièrement dans les cas de Wang Ming et Wang Shivei, la campagne de rectification fut une tentative non seulement de développer une herméneutique au moyen du lien exégétique, mais de rendre cette herméneutique totalement hégémonique comme un langage distinguant l'éclairé du non éclairé, et séparant le bon communiste des apostats ou des dissidents. C'est en ce sens que l'on peut dire que Yan'an fut à la fois une haute sphère morale, et un moment machiavélique ${ }^{69}$. Le lien exégétique fut en réalité la vision de Mao, traduite par les moyens de sa propre version de la dialectique,et convertie en pouvoir symbolique à travers des séances d'apprentissage excessivement épuisantes suivant des procédures éducatives élaborées. Sa force (qui pouvait devenir sa faiblesse) fut qu'il n'accepta aucun élément extérieur, et ce à tous les niveaux, même si celui-ci pouvait s'appliquer avec souplesse et s'adapter aux conditions locales. Lorsque, en définitive, le Parti communiste chinois triompha et que effectivement il mit le monde chinois sens dessus dessous, l'objectif suivant fut non seulement d'universaliser cette vision et de l'adapter aux nouvelles circonstances mais également de mettre en déroute tous les modes de pensée opposés non seulement à l'intérieur du parti mais aussi dans tout le pays. Seulement lorsqu'il sort par la porte, la contestation, comme le péché, rentre par la fenêtre, l'imposition hégémonique détruit son propre pouvoir symbolique. Lorsque les choses allèrent mal, il n'y eut finalement plus personne d'autre à blâmer que le parti. Et plus récemment, le parti est parvenu à symboliser en effet aux yeux des chinois tout ce qui va mal et est répréhensible. Le rétablissement du mythe de Yan'an durant la révolution culturelle est à ce propos significatif. L'orthodoxie de la pensée de Mao se transformant en une sorte de réalisme magique dont les conséquences furent véritablement tragiques.

Les réformes engagées après 1979 affaiblirent le monopole du parti sur la vérité. Et ceci a conduit à une situation à laquelle le parti était mal préparé. Diversité des opinions, logique de démocratisation posèrent un défi à l'orthodoxie dialectique. Pour tenter de remédier à cette quadrature du cercle, les autorités acceptèrent la logique de la première sans sa pratique, et l'orthodoxie de la seconde mais sans son principe. En fait, 
le parti retint le plus mauvais choix parmi les possibles. Il réaffirma son monopole sur la vérité juste au moment où les événements l'amenaient vers une "pluralisation"70.

Historiquement Yan'an ressemble aux phases radicales des Révolutions française et anglaise, mais il réussit là où les autres échouèrent. "L'idéal à atteindre fut celui d'une société de non spécialistes s'aidant mutuellement pour atteindre la vérité à travers la communauté"71. Il représenta un idéal qui ne rejetait pas seulement le féodalisme et le capitalisme mais également l'individualisme qui pouvait mener à l'anarchie. Il offrit à la place la raison dialectique, appliquée aux conditions chinoises, dans les circonstances communautariennes du mutualisme, et requérant pour s'accomplir la discipline du texte. En ce sens, Yan'an, comme les autres communautés utopiques, fut considéré par ses fondateurs comme représentant le triomphe de la volonté collective sur la compétition individuelle. L'universaliser revenait à changer la nature même de la vie en société. Concernant les complexités pratiques du développement, Yan'an avait finalement peu de choses concrètes à offrir. Son capital symbolique se dissipa en dépit des efforts radicaux entrepris pour le faire revivre durant la Révolution Culturelle ${ }^{72}$. Il devint le mythe de la légitimation de la Révolution, mais uniquement sous une forme ritualisée et dénuée de véritable signification ${ }^{73}$. Yan'an séduit ceux qui cherchaient à combiner radicalisme, militantisme moral, et discipline politique au sein d'un ensemble rationnel. Par contraste aujourd'hui, les régimes socialistes dépérissent et la Chine est confrontée au vide laissé par l'après Tiananmen. La seule et unique signification qui demeure de Yan'an aujourd'hui est l'ombre qu'il jette sur le désir et le besoin de démocratisation. Tiananmen : la ville à l'intérieur de la place Rien ne pouvait être plus provocateur que les événements qui ont eu lieu sur la place Tiananmen, en dépit de l'auto-discipline et du calme des manifestations. Ils commencèrent en apparence comme un hommage à Huo Yaobang qui avait soutenu à différentes occasions le nouveau mouvement pour la démocratie et avait été contraint de s'incliner. En soi ceci n'était pas une provocation très grave mais les Yan'anites traditionalistes au pouvoir ont rapidement compris que c'était la preuve que quelque chose était en train de se passer. Ce que la vieille garde vit et reconnut immédiatement, ce fut la naissance d'un nouveau discours, non pas simplement d'un dialogue entre intellectuels, mais d'un discours provenant du lieu le plus sensible et le plus symbolique de Chine concernant le pouvoir. C'est là, en effet, face à la grande porte de la cité interdite, où les empereurs Ming créèrent un espace qui témoignait que le mandat impérial reflétait sur terre l'empire céleste, là où eurent lieu les manifestations du 4 mai 1919, là où la République du peuple fut proclamée, et là où une grande manifestation de deuil à l'occasion de la mort de Zhou Enlai eut lieu, c'est à dire le lieu par excellence des multiples symboles du passé, qu'un projet démocratique venait d'être formulé. Il leur aurait fallu reconnaître politiquement qu'une nouvelle société était en train de prendre forme, qu'elle devait être institutionnellement articulée, et que la "purification" des élites, une plus grande responsabilité, un véritable pluralisme et le changement institutionnel étaient inévitable dans cette logique. Se sentant en danger, les vieux Yan'anites au pouvoir comprirent la force du simulacre formulé sur la place Tiananmen lors de ce printemps 1989 et capable en générant un nouveau capital symbolique d'obtenir le soutien massif des travailleurs et des paysans, y compris au sein du parti. Ce que Mao et théoriquement tous ses partisans avaient toujours refusé fondamentalement, et que Deng Xiaoping craignait, était en train d'advenir avec la formulation d'une alternative redicale. La vieille garde Yan'anite joua alors de ses muscles arthritiques. Comme en 1979, 1968, 1967, sa première réaction fut d'écraser le mouvement estudiantin avant 
qu'il ne prenne de l'importance. En dépit du caractère limité des revendications formulées par les étudiants (plus soucieux de discuter avec les autorités des réformes démocratiques en termes de processus politique que de mesures concrètes) les autorités savaient que le dialogue pouvait mettre fin à l'ordre qu'elles représentaient. Déjà, bien que cela ne fut pas systématique, quelque chose comme un lien exégétique avait commencé à apparaître dans les dortoirs universitaires, dans les cantines, et partout où l'on pouvait se réunir. En outre une "structure" s'était formée au sein même du vaste espace de la place et fut animée par les étudiants en contenant potentiellement dans ce simulacre révolutionnaire nouveau et démocratique, une version miniature d'une société qui pouvait prendre forme, une société certes un peu primaire, organisée plus ou moins spontanément, mais une société démocratique.

67 La place devint une ville à l'intérieur de la ville, une société à l'intérieur d'un Etat, n'émergeant pas des cavernes mais de tentes, d'une mer de tentes, avec dans cette mer, des îles de drapeaux rouges et de slogans. Ce fut là encore un théatre public, une véritable Agora. On diffusa de longues déclarations et exhortations par haut-parleurs, certains portés par des étudiants, d'autres accrochés au sommet du mémorial des martyrs mais toujours audibles. Et l'on assista là à une sorte de tentative de reprise de possession du pouvoir par la classe "héritière" des élites potentielles refusant d'attendre passivement plus longtemps que son tour arrive. Cette classe demanda à être associée à la manière dont le pouvoir était défini. La place Tiananmen devint, pour quelques semaines, tragiquement trop brèves, une démocratie primitive, et une communauté. Elle s'étendit à la place elle-même et à ses rues adjacentes ainsi que ses alentours. Dans cet espace elle devint une structure de pouvoir semi autonome. L'intérieur du mouvement resta ordonné. Différents secteurs furent isolés, nécessitant pour y entrer un laissez-passer tamponné par un responsable. Chaque quartier avait ses tentes et ses abris, ainsi qu'une partie plus résidentielle avec des tables communes pour se restaurer. A l'intérieur, au milieu d'un enchevêtrement de literie, de pots, et de casseroles, les gens lisaient, discutaient, écrivaient, faisaient circuler des tracts, et s'organisaient. Comme à Yan'an ceci fut structuré autour des universités et des écoles. Le savoir devint un permis pour exprimer une opinion. Certains étudiants représentaient les universités et les instituts de Beijing. Les autres venaient de la Chine toute entière, profitant de la décision du gouvernement de mettre à leur disposition des trains gratuits, et de leur donner certains privilèges facilitant leur voyage vers la place (privilèges qui allaient être supprimés après la loi martiale, empêchant ceux qui en avaient bénéficiés de retourner effectivement chez eux). Les étudiants aménagèrent des latrines et un système d'évacuation des ordures. La nourriture fut fournie en grande quantité par les usines, et les villages ruraux. Le soutien provenait aussi bien des villes que des campagnes. Les transports furent organisés avec tout ce qui pouvaient être utilisés : des camions, des bus, des voitures. Juste au moment où le mouvement sembla un peu hésiter, la grève de la faim suscita une grande sympathie de la part du public. Des installations médicales furent immédiatement montées, des médecins, des infirmières, et des aides soignantes se précipitèrent sur le site vêtus de blanc, portant des masques de chirurgien et des bonnets. Des "routes" furent ouvertes entre les zones de campement et laissés dégagées pour les ambulances. L'eau fut amenée par grands camions. La nourriture et les boissons fraîches ainsi que toutes sortes de literies, étaient données par les citoyens. Des fonds étaient collectés et distribués, des affiches imprimées, des journaux distribués, et un service postal interne fut établi, des surveillants furent désignés, des tribunaux furent instaurés pour 
maintenir la loi, l'ordre, etc. Une université populaire fut organisée, les documents pour la lecture furent imprimés et distribués, on fixa les relations entre l'intérieur et l'extérieur, on organisa des processions orchestrées jour et nuit. La scène théâtrale se situa autour du grand obélisque, le monument des martyrs de la révolution dont les marches mènent à un parapet en pierre. Tout le monde pouvait s'asseoir sur les marches inférieures, mais il fallait montrer une autorisation pour accéder au parapet. Au niveau supérieur on trouvait les représentants des sept ou huit personnes du comité qui représentaient le sommet de la direction du mouvement étudiant et qui étaient composés des représentants des comité d'étudiants. Une sorte de champ magnétique existait tout autour du monument qui attirait chaque campus d'université, constituant l'équivalent d'un espace public. Dans chaque centre révolutionnaire, les gens se rassemblaient entourés par des affiches, des forêts de bicyclettes, et l'incontournable haut-parleur public. Chaque centre fut une version en miniature de la place Tiananmen. Ici aussi les haut-parleurs diffusaient des déclarations entrecoupées par des nouvelles du "front", des annonces concernant l'organisation, etc. Les affiches murales pouvaient être drôles, et la calligraphie féroce. Certaines de ces affiches étaient en anglais. Ainsi de la place Tiananmen rayonna en direction de chaque université, un langage et un discours propre à la nouvelle révolution. Recueillis par des foules en attente, ces discours étaient rediffusés par chaque campus. Les étudiants eux-même partaient et revenaient constamment, leurs bicyclettes prêtes à partir, attendant les instructions. Dans les dortoirs des étudiants cachés aux vues du public et restant sur leur garde à cause de la police, imaginaient et évaluaient des stratégies et des tactiques en essayant de systématiser les changements de situation. Ils furent rejoints dans leur tentative par de jeunes enseignants et professeurs. Les vieux professeurs bien que sympathisants restèrent quant à eux à l'écart. Sur la place elle-même, du haut du parapet le plus élevé du mémorial des martyrs, les discours, les annonces de programmes et d'ordre du jour étaient à portée de voix et dans le champ de vision de la foule. Les gens discutaient des théories de la démocratie, pendant que l'on jouait audessus leurs têtes des extraits de la cinquième et de la neuvième symphonie de Beethoven, l'internationale, et bien sûr de la musique pop des années soixante. Tout comme Yan'an, la place Tiananmen devint une communauté totale. Elle devint ce qu'elle voulait être : un cours, une leçon de démocratie, une praxis, un exemple de la manière dont la démocratie peut surgir grâce au pluralisme de la société civile qu'elle affirmait représenter. Les groupes de manifestants qui marchaient sur les principales routes et passaient par la place, suivaient les lignes soigneusement marquées par des cordes et étaient guidés par des étudiants portant un brassard rouge au bras. Tous les types d'unités étaient représentés : travail, école, institut. Chacun portait drapeaux et bannières. Les journalistes demandaient la liberté de la presse et la fin de la censure. Les chercheurs appelaient à plus de liberté à la place du contrôle. Les ouvriers venaient des quelques plus grosses usines de Beijing. Il y avait des cadres et des membres des branches locales du parti communiste. Mais il y avait bien sûr aussi des divisions. Les néo-autoritaristes croyaient à la démocratisation du parti communiste. Les "démocrates radicaux" préféraient penser à une solution apparentée au gouvernement constitutionnel du 19ème siècle. Quand on leur demandait s'ils acceptaient le principe "un homme une voix" les gens avaient tendance à dire oui. Lorsque l'on leur demandait s'ils voulaient que chaque paysan ait le droit de vote, les mêmes personnes hésitaient. Personne n'avait d'idées très précises sur le genre de démocratie qui pouvait fonctionner en Chine. mais tout le monde s'accordait sur le fait que la démocratisation 
devait commencer. Les événements tragiques du 4 juin 1989 sont bien sûr connus de tous. La vieille garde brisa le mouvement qui exerçait un pouvoir encore inexpérimenté. Dans un premier temps les unités légères de l'armée se déversèrent par les portes de la cité interdite. Puis les colonnes de l'armée, armées d'armes automatiques et de tanks se déployèrent à partir des points Est et Ouest de la place, le long de l'avenue Changan. De l'extérieur du grand hall du peuple d'un coté et du musée de la révolution de l'autre, des unités de l'armée populaire de libération, vinrent "libérer" la place de ses libérateurs. Le pouvoir refusa d'accéder aux demandes de ceux qui voulaient redéfinir cette espace en termes de démocratie, et rejeta violemment la demande de la future génération ( c'est à dire de ceux qui, dans les rhétoriques, étaient les bénéficiaires désignés de la révolution communiste). Aujourd'hui la place reste sévèrement gardée, vide de cette exubérance, de cette vibration, de cet esprit et du courage des nombreux jeunes gens qui avaient demandé à leur gouvernement d'entamer un processus, d'entreprendre un dialogue et qui ont rencontré à la place, des mitrailleuses et des tanks.

Tiananmen et la momie de Yan'an Si l'on a perçu à Tiananmen un nouveau discours sur le point de naître, et le début d'une nouvelle expression démocratique du capital symbolique, on y a vu aussi la dissolution finale de cette unité des contraires qui pendant si longtemps a symbolisé Yan'an, contrat originel entre le pouvoir et les principes. En effet si Yan'an fut une république éducative, dans laquelle chacun était en quelque sorte un étudiant, à Tiananmen ce furent les étudiants qui apprirent à leurs éducateurs que le vieux contrat social était mort et que le communisme en Chine était comme les restes de Mao, une momie exposée dans une crypte. On peut en effet visiter maintenant le mausolée et ensuite aller à quelques pâtés de maisons de là, au plus grand magasin du monde : le Kentucky Fried Chicken. Lequel a réalisé de très bonnes affaires tout au long des événements. En fait les deux grandes effigies du colonel Sanders qui se tiennent à l'entrée du magasin rivalisent en rondeurs et en vacuité dans l'expression avec le portrait de Mao regardant en bas du haut de son perchoir, accroché au mur de la cité interdite. Ce fut en direction de ce portrait de Mao que les étudiants avaient placé leur déesse de la démocratie. Habillée d'une robe blanche en plastique et en polystyrène, tenant entre ses mains le flambeau de la liberté qui arrivait sensiblement sous le nez du vieil homme, son grand corps presque gracieux légèrement tourné comme si elle ne pouvait supporter de regarder le portrait, elle tenait tête au vieil homme et à tout ce qu'il représentait. Son visage était serein, presque triomphant, encerclé et couronné de drapeaux rouges et peinte de slogans en faveur de la révolution $^{74}$. En dessous se trouvaient les tentes de ceux qui étaient ses gardiens. Aimant pour les foules, elle fut aussi la première cible des chars qui firent irruption sur la place. Mais même à la lumière du jour suivant, alors qu'elle était étendue, écrasée, en pièces, toute innocence évanouie, sa présence continuait à définir cet espace vidé par la force brutale. Elle reste la présence absente qui attend d'être comblée, en dépit des gardes et des soldats. Et personne ne peut marcher sur cette place qui retentit encore du bruit des chars et des cris d'une génération perdue sans se souvenir de ce qui a été perdu.

Malgré les efforts énergiques du parti et de l'Etat pour stigmatiser le mouvement comme contre-révolutionnaire, ce mouvement demeure fondamentalement révolutionnaire. En proclamant la nécessité d'un nouveau départ, en demandant de tout recommencer, la place Tiananmen symbolise l'établissement d'un nouveau contrat social, d'une puissante fiction normative dans la réalité empirique, géneratrice d'une 
véritable occasion de renaissance pour le capital symbolique. Ce qu'ont montré les événements c'est combien les principes établis à Yan'an ont été maltraités et corrompus par une praxis politique d'un Etat qui s'est déshonoré par une série continue d'abus contre son peuple. Tiananmen a "déconstruit" la structure de l'Etat et $\mathrm{du}$ socialisme guaanxi. Tiananmen a cherché en remplacement non pas une solution toute faite mais un processus, une cinquième modernisation, une démocratisation, conduisant vers une politique digne de ce nom, un système politique s'auto-validant, et amenant à l'élaboration de nouveaux discours politiques. ANNEXE Méthodologie de la recherche L'analyse de Yan'an est fondée sur ce que l'on pourrait appeler une ethnographie de la mémoire, les événements historiques sont vus à travers les survivants de cette expérience (pour lesquels Yan'an reste un moment d'intense implication personnelle). Nous avons pu avoir accès à de nouveaux matériaux documentaires. Nous nous sommes rendus compte en interrogeant des survivants de cette période qu'un entretien classique en tête à tête n'était pas satisfaisant. Un système de groupe s'entretenant avec les survivants dans leurs foyers là où c'était possible, fonctionnait mieux. Environ cent cinquante survivants de cette période ont été interviewés, et parmi ceux-ci, le garde du corps personnel de Mao de l'époque, l'un de ses secrétaires personnels, des enseignants, des journalistes, des écrivains, des artistes, des danseurs, des musiciens, des acteurs, des actrices, des réalisateurs de films, des photographes, des personnes chargées de mener la propagande, des commandants de l'armée rouge, des soldats, des directeurs et des fonctionnaires des diverses académies, écoles et universités. Bien sûr, même dans les meilleures conditions, mis à part le problème des mémoires défaillantes ou des souvenirs erronés, la réalisation d'un entretien ne se fait pas sans difficulté. Les informations recueillies sont à la fois incertaines et allusives, n'obéissant ni au genre de l'histoire orale symbolisée par « l'archéologie » de Vansina, ni aux conditions ordinaires de l'entretien. Trop, parmi eux, sont devenus des adeptes, on pourrait presque dire des professionnels, de la dissimulation, occultant ce qu'ils préfèrent ne pas divulguer puisqu'en maintes occasions c'est à cette capacité qu'ils ont dû leur survie. Une ethnographie de la mémoire, et spécialement une phénoménologie historique, nécessitent des entretiens et des ré-entretiens approfondis et soigneusement menés. Les premiers entretiens visaient à obtenir un résumé des conditions physiques et personnelles, insistant sur les aspects et détails de la vie ordinaire : Comment en êtes-vous arrivé à vous joindre à la révolution? Avez-vous annoncé votre décision à votre famille ? Comment avez vous fait pour parvenir à Yan'an? Une fois sur place combien de fois par jour mangiez-vous, et que mangiez vous? Est-ce que les femmes préparaient les repas? Combien de personnes partageaient votre "caverne" ? Que se passait-il quand vous étiez atteint de troubles digestifs? A quoi utilisiez-vous l'argent? Que se passait-il si vous désiriez une femme/un homme? Quels ont été les moments les plus effrayants/de plus grand désespoir? A quelle distance étiez-vous des latrines? Et ainsi de suite, passant au fur et à mesure d'un examen rétrospectif du quotidien à des questions d'ordre plus politique : êtes-vous passé par la rééducation? Quelles questions vous a-t-on posées? Où avez vous été "exposé" durant la Campagne de Sauvetage? Vous souvenez vous d'espions découverts durant cette campagne? Quels étaient vos principaux doutes? Qui étaient vos meilleurs amis? L'équipe de recherche fut dirigée par un Chinois américain. Tous les autres membres de l'équipe étaient chinois et parlaient l'anglais couramment. Cette équipe était constituée d'un anthropologue de l'Académie chinoise des Sciences, d'un politiste de l'Institut des Etudes Américaines de l'Académie Chinoise des Sciences 
Sociales, et d'un étudiant en littérature anglaise de l'Université de Pékin. De temps en temps d'autres personnes se joignaient temporairement à cette équipe, et travaillaient en étroite collaboration à la fois sur les documents et sur d'autres matériaux ${ }^{75}$. Les entretiens furent longs, et, comme tout le monde y participa, ils prirent plutôt l'allure de séminaires. Les personnes furent, autant que possible, interviewées plusieurs fois et spécialement celles qui jouèrent des rôles clefs dans Yan'an ou ceux qui avaient une connaissance exceptionnelle de certains aspects de cette période, comme Dai Qing, une admirable reporter qui nous fournit la plupart des informations sur Wang Shiwei. L'un des entretiens les plus remarquables, mené sur la principale base militaire proche de Beijing avec un général à la retraite qui avait été sous les ordres de He Long, nous permit d'avoir une idée assez précise de l'emploi réciproque de la torture entre les différentes factions et branches à l'intérieur de l'armée rouge elle-même. Nous pûmes également bénéficier de l'aide et de la participation de spécialistes de la Chine et plus particulièrement du professeur Tony Saich, directeur de l'Institut de sinologie de l'université de Leiden qui avait accès aux matériaux documentaires et qui est devenu co-auteur du livre en anglais qui reprendra de façon plus complète l'analyse des présents matériaux réunis ici en avant première pour cet article ${ }^{76}$. Le même système d'entretiens fut utilisé par une équipe de recherche légèrement différente en qui concerne la place Tiananmen. Ici les matériaux ont été recueillis sur la base d'observations directes et d'entretiens avec les grévistes de la faim, les leaders politiques, les organisateurs des différentes universités, etc.

\section{NOTES}

1. Cette recherche effectuée dans le cadre d'une étude sur la révolution chinoise n'aurait pu être menée à bien sans l'aide du Comité pour l'échange scientifique avec le peuple de la République de Chine, le département d'histoire de l'université de Pékin, et l'Institut du marxisme-léninisme de la pensée Mao Zédong de l'Académie chinoise de sciences sociales. Je suis tout particulièrement reconnaissant de l'aide précieuse que m'ont apportée les professeurs Su Shaoxi, Luo Ronquo, et mes collaborateurs de recherche, Michelle Chua, Zhang Meng, Song Xiaoping, and Zhao Yi. Le présent texte a été traduit de l'américain par Richard Brousse, Didier Bigo et Ayse Ceyhan.

2. Parti communiste chinois.

3. Pour une analyse du concept de prédémocratique voir D. E. Apter, The Politics of Modernization, Chicago, University of Chicago Press, 1972 ; Rethinking Development, Beverley Hills, Calif., Sage Publications, 1987.

4. Voir la définition donnée infra.

5. Cette force du symbolique se retrouve dans chaque aspect de la politique, même aujourd'hui, dans la politique étrangère comme dans la politique intérieure. Voir à ce propos Kenneth Lieberthal, "The Foreign Policy Debate in Peking as Seen Through Allegorical Articles, 1973-76" in The China Quarterly, No. 71, September 1977, pp. 528-554. 
6. Ce terme est repris dans le sens donné par Pierre Bourdieu, Esquisse d'une théorie de la pratique, Genève, Droz, 1972. Bourdieu l'emploie pour se référer à l'honneur, au prestige, aux règles de réciprocité et d'échange de biens non économique mais hautement chargé en valeurs symboliques. Le terme de capital symbolique utilisé ici fait référence également aux mythes et théories mobilisées dans les recontructions du passé et les projections du futur, leur donnant une densité et les glorifiant au moyen de métaphores et métonymies, et les enchassant dans les textes et la logique, à travers le language et des discours à caractère performatif.

7. Il n'est pas de mon propos de rentrer ici dans les détails de l'organisation ni de décrire les structures politiques et administratives de Yan'an. Bien qu'en partie datée, l'une des principales sources à ce sujet reste le livre de Mark Selden, The Yenan Way, Cambridge, Harvard University Press, 1971.

8. Voir Jean Baudrillard, Simulacres et Simulation, Paris, Editions Galilée, 1981.

9. Le principal point de départ analytique pour cette étude réside dans "une phénoménologie structurale".Voir en particulier Paul Ricoeur, Lectures on Ideology and Utopia, George H. Taylor, (ed.), New York, Columbia University Press, 1986, and The Rule of Metaphor, Toronto, University of Toronto Press, 1979.

10. Voir Claude Lévi-Strauss, "The Story of Asdiwal" in E. R. Leach. (ed.), The Structural Study of Myth, London, Tavistock, 1967, pp 1-48.

11. Un deuxième point critique fut atteint durant l'intense période d'activité idéologique de la révolution culturelle. Ensuite, à l'image de l'affaiblissement du capital symbolique, le principe a décliné et toute prétention liée à ce principe a été abolie par les événements de la place Tiananmen. Pour une discussion sur la renaissance du symbolique, voir Tang Tsou, The Cultural Revolution and the Post-Mao Reforms, Chicago, University of Chicago Press, 1986. Voir également Roderick MacFarquhar, The Origins of the Cultural Revolution, Oxford, Oxford University Press, 3 volumes.

12. Voir Bernard Yack, The Yearning for Total Revolution, Princeton, Princeton University Press, 1988.

13. Ceci fut totalement ignoré par les étudiants et les militants qui campaient là pour construire une "ville à l'intérieur de la place". Voir dernière partie.

14. Voir David E. Apter, "Mao's Republic", in Social Research, Vol. 54, no. 4, winter, 1987.

15. Rappelons qu'à Yan'an les gens habitaient dans des habitations troglodytes, dans des "cavernes".

16. Ce mouvement fut également préoccupé par les frontières : frontières morales, frontières géographiques et ethniques, frontières du corps (y compris les barrières sexuelles). Il est intéressant de noter que la métaphore qui compare la chine à un malade pollué dont le sang est empoisonné, est une figure commune dans la littérature, aussi bien chez Lu Xun que dans les oeuvres d'écrivains moins connus. Snow écrit également dans Red Star Over China, "Cela peut paraître quelque peu évangélique, je suppose, mais personne ne pourrait voir ces jeunes vies héroïques sans imaginer qu'un homme en Chine ne nait pas mauvais, mais avec d'infinies possibilités de personnalité. Mao a publié tout d'abord un ouvrage sur "la bonne santé physique". Cela contraste avec l'image des paysans abrutis ou des mandarins épuisés. Il était également, spécialement à Yan'an, fait un large accueil dans les rangs et les cellules communistes au puritanisme sexuel (excepté dans les rangs les plus élevés). Une observatrice aussi avertie que Agnes Smedley, qui s'est toujours intéressée à la relation entre sexe et liberté, décrit les moeurs sexuelles ainsi : « un jour un caméraman de passage me 
demanda : "Est-ce que l'Armée Rouge fournit des préservatifs aux soldats pour qu'ils se protègent des maladies vénériennes ?". Cette question illustrait parfaitement le profond gouffre qui existait entre les hommes de l'Armée Rouge et les hommes venant d'Amérique. L'Armée rouge était si pauvre qu'elle manquait même d'argent pour subvenir aux besoins essentiels de son existence, elle n'avait jamais entendu parlé de préservatifs. Toutes les femmes chinoises se marient très jeunes, et la vie sexuelle pour les soldats signifiait automatiquement le viol de femmes mariées. Le viol d'une femme étant un acte criminel dans l'armée, et la prostitution étant interdite, ils étaient contraints à l'abstinence. Lorsque j'ai expliqué cela au caméraman il m'a regardé avec une expression d'horreur "; voir See Agnes Smedley, China Correspondent, London, Pandora Press, 1984, p.130. Le commentaire peut paraître naï. Les officiers supérieurs s'arrangeaient pour enlever de jeunes femmes arrivant à Yan'an.

17. Voir Paul Ricoeur, The Symbolism of Evil, Boston, Beacon Press, 1967.

18. Voir Paul Ricoeur, The Symbolism of Evil, op cit.

19. D'où les efforts conscients entrepris pour remplacer le Confucianisme par le Maoisme, voir Joseph R. Levenson, Confucian China and Its Modern Fate, Berkeley, University of California Press, 1968. Voir aussi D. E. Apter, "The New "Mytho-logics" and the Spectre of Superfluous Man", Social Research, 52, summer, 1985, pp 269-307. 20. Le "capital symbolique" qui nous intéresse ici s'est constitué à ce moment là. (Nous sommes moins intéressés par Yan'an comme mythe légitimant du Parti communiste chinois). Nous n'essayons pas de comprendre les circonstances immédiates et les événements convulsifs que Mao et ses camarades ont vécu, compris et transcendé, en utilisant un modèle fonctionnel. Comme nous n'essayons pas non plus dans cette approche de favoriser ici une version dérivée d'une théorie de la modernisation. Nous n'opposons pas le communisme au traditionalisme, le néo-féodalisme à la modernité, ni $n$ 'examinons les transformations des normes et valeurs des structures sociales et des classes, des perceptions et des motivations dans les termes d'un modèle intégrateur. En fait le point de vue favorisé ici place le capital symbolique au centre, met l'accent sur la rationalité collective issue du processus du "lien exégétique", dans une tradition d'analyse que Pareto décrivait comme analyse des symboles et significations plutôt que des causes et effets. Le point central n'est pas de décrire les entreprises individuelles mais de comprendre leurs contributions à l'action collective.

21. Bien que je me sois rapporté aux principaux textes eux-mêmes, parmi les plus importants interprètes dont j'ai consulté les travaux, deux ressortent : Joseph R. Levenson et spécialement son magistral ouvrage, Confucian china and Her Modern Fate, Berkeley, University of California Press, 1968, et plusieurs écrits de Stuart Schram, plus particulièrement : The Political Thought of Mao Tse-tung, New York, Praeger, 1969 ; The Thought of Mao Tse-tung, Cambridge, Cambridge University Press, 1989, et son introduction à Li Jui, The Early Revolutionary Activities of Comrade Mao Tse-tung ,White Plains, M. E. Sharpe, 1977.

22. Voir Bernard Yack, op. cit.

23. Pour une première étude montrant la manière dont ce processus opère dans les conditions actuelles voir : D. E. Apter et Nagayo Sawa, Against the State, Cambridge, Harvard University Press, 1984. Pour une analyse "système de mobilisation", voir D. E. Apter, Choice and the Politics of Allocation, New Haven, Yale University Press, 1971. Voir également, D. E. Apter, Rethinking Development, Beverly Hills, Calif., Sage Publications, 1987. 
24. Pour une première discussion autour de cette question voir D. E. Apter, "Mao's Republic", in Social Research Vol. 54, No. 4, Winter 1987, pp. 691-729.

25. Ce qui est examiné ici c'est la manière dont les engagements révolutionaires ont supplanté les priorités de la vie quotidienne et se sont puissament opposés aux calculs les plus ordinaires. Bien sûr, comme j'essaye de le montrer en examinant de plus près la situation, nombre de ces calculs étaient consacrés à changer les règles elles-mêmes. Il est donc vrai de dire que Yan'an représentait une implosion normative réduisant à néant les prétentions normales concernant la vie quotidienne, cela s'est produit d'une façon qui a brisé l'acteur rationnel individuel, puis l'a rassemblé et unifié sous les règles de l'acteur collectif.

26. Voir Michel Foucault, Discpline and Punish, New York, Vintage Books, 1979.

27. Le capital symbolique, comme son équivalent économique plus familier, peut-être "épargné", et "investi". Il peut être utilisé pour définir les obligations contractuelles. Mais politiquement il diffère du capital économique dans la mesure où sa signification dépend de sa capacité à mobiliser et à collectiviser de façon effective un groupe de militants au delà de la clientèle.

28. Voir James Clifford, "On Ethnographic Surrealism" in Comparative Studies in Society and History, 23 October 1981, pp. 539-564.

29. Les murs ont été reconstruits, en partie après avoir été détruits par les bombardements japonais durant la guerre.

30. Ces événements ne paraissaient pas seulement miraculeux pour les Chinois mais également pour les observateurs extérieurs. Ecrivant sur la Longue Marche, Snows dit :

" Un aperçu statistique de la Longue Marche est impressionnant. Il montre que ce fut en moyenne presque une escarmouche par jour, où que ce soit sur le chemin, pendant 15 jour entiers ont été consacrés à des batailles majeures. 235 jours ont été passés à marcher de jour, et 18 à marcher de nuit. Sur 100 jours de haltes - beaucoup d'entre eux ont par ailleurs été marqués par des escarmouches - 56 ont été passés dans le nord-est du Szechuan, laissant seulement 44 jours de repos pour une distance d'environ 5000 miles, soit une moyenne d'une halte pour 114 miles. L'étape quotidienne moyenne était d'environ 24 miles, un rythme phénoménal pour une grande armée et ses transports sur l'un des terrains les plus risqués sur terre". Voir, Red Star over China, New York, Random House, 1938, p. 348.

31. Lorsque l'on retourne à Yan'an aujourd'hui, il est difficile de se représenter à quoi cela ressemblait. Il reste quelques vestiges de la période. Au sommet des collines qui dominent la ville de Yan'an où la rivière forme une boucle, on peut encore voir l'ancienne caverne des mille Bouddhas où les communistes avaient installé leurs presses d'imprimerie. L'ancienne Pagode, symbole de Yan'an, et couverte de boutons par les gardes rouges durant la révolution culturelle, est toujours là. Cependant la majeure partie de Yan'an se compose d'immeubles en béton à l'architecture sinostaliniste. Elle est loin de ressembler à l'ancienne ville fortifiée où les communistes s'étaient retirés.

32. Il faisait habituellement ou trop froid ou trop chaud. Les gens vivaient à huit ou plus dans une caverne. Leur nourriture était principalement constituée de millet. Ils possédaient quelques outils pour écrire. Les textes étaient imprimés avec la presse d'imprimerie locale qui avait été transportée durant la Longue marche. La zone entière était stérile et balayée par les vents. Voir la brève faite par Andrew Watson, Mao Zedong and the Political Economy of the Border Region, Cambridge, Cambridge University Press, 1980. 
33. Yan'an était techniquement subordonné au gouvernement nationaliste. Mais après l'accord de 1936 avec Chiang Kai Shek, Yan'an devint une communauté autonome avec sa propre économie, son propre système fiscal et monétaire, sa propre administration et son propre gouvernement. Subissant périodiquement un blocus de la part des nationalistes (même durant la bataille contre les japonais), Yan'an a été amené à créer ses propres approvisionements en nourriture, en armes et en matériels, et spécialement en 1941. Le plus impressionnant fut de ce point de vue les réalisations concrètes. Les efforts menés pour transformer les steppes en zones rurales productives ont conduit à une telle réussite que les idées de Mao sur la production agricole ont été refaçonnées par ce qui est arrivé. La brigade Nanniwan, par exemple, unité militaire envoyée dans la "brousse" pour la "défricher", et devenant ainsi quasi-indépendante, devint partie de la légende de Yan'an.

34. Voir Hua Chang-Ming, La condition feminine et les communistes chinois en action, Yan'an 1935-1946, Paris, Editions de l'Ecole des Hautes Etudes en Sciences Sociales, 1981, pp. 19-21.

35. Il y eut des premiers prototypes, comme la forteresse de la guérilla dans les montagnes de Jinggaan. La base de Jiangxi fondée en 1931 servit de modèle à Yan'an. Ce fut l'attaque et l'encerclement de cette base par les forces nationalistes en octobre 1934 et dont l'armée rouge réussit à s'échapper qui a conduit à la Longue Marche qui se termina elle-même un an plus tard dans la province de Shaanxi.

36. Bao'an fut plus tard renommée Zhidan en l'honneur du chef héroïque qui selon la légende mourut au combat et que Snow décrit comme le robin des bois local. Voir red Star Over China, op. cit., p. 210.

37. Voir Seldon, op. cit.

38. En Chine la tradition de bases rebelles semi-autonomes est très ancienne. Voir pour cela la description qu'en fait dans son ouvrage Jonathan D. Spence, The Search for Modern China, New York, W. W. Norton, 1990, pp. 22-23.

39. Young Men's Christian Association.

40. Voir Jane L. Price, Cadres, Commanders, and Commissars, Boulder, Colorado, Westview Press, 1976.

41. Ibid, pp. 135 - 172.

42. Dans le programme de Kangda, Mao enseignait la stratégie et les tactiques de l'armée rouge, le matérialisme dialectique et, avec plusieurs autres personnes, les cours sur les dialectes. Ibid, p. 140. Pour une discussion du travail de Ai Siqi, voir Joshua A. Fogel, "Ai Siqi : Professional Philosopher and Establishment Intellectual" in Merle Goldman, T. Cheek and Carol Lee Hamrin, China's Intellectuals and the State, Cambridge, Harvard University Press, 1987, pp. 23 - 41.

43. Voir Martin King, Whyte Small groups and political rituals in China, Berkeley U. C. press, 1974, pp. 32 - 33.

44. Après la Révolution Culturelle, Kang Sheng devint un des "scélérats" de la "bande des quatre".

45. Les entretiens en eux-mêmes ne doivant pas être considérés comme une description du passé mais comme une reconstruction de ce dernier. Bien que la documentation sur la période 1937 - 1971 devienne plus accessible, il est toujours difficile de démêler ce qui fut constitué comme mythe à l'époque de ce que furent réellement les événements. 46. Voir Mao Zedong, "Reform Our Study", "Rectify the Party's Style of Work", "Talks at the Yan'an Forum on Literature and Art" in Selected Works, Vol. 3, Peking, Foreign Languages Press, 1967. 
47. Mao a souvent donné l'impression que ses idées lui avaient été données par le peuple, et qu'il les avait seulement organisées. Par exemple, une "authentique" femme écrivain prolétarienne bien connue (qui se situait dans la tradition de Gladkov) et avec laquelle Mao s'est entretenu d'art et de littérature durant quelques trois semaines, nous affirma lors d'un entretien, que Mao posait ses questions d'une telle façon qu'il lui avait amener les mots à sa bouche. Mais elle était convaincue, comme cela c'était passé pour elle, que les thèses de Mao sur les arts et la littérature avaient été "tirées du peuple".

48. Voir Joseph R. Levenson, Confucian China and its Modern Fate, Berkeley, University of California Press, 1968. Voir aussi Franz Schurmann, Ideology and Organization in Communist China, Berkeley, University of California Press, 1966.

49. Voir Liu Shaoqui, "How to be a Good Communist".

50. Il y avait autour de Mao des glossateurs et des commentateurs représentant une élite dont le travail consistait à s'assurer que les vérités et les vertus incorporées dans les textes sélectionnés n'étaient pas seulement étudiées mais uniformément comprises et auxquelles ils devaient souscrire comme tous les autres. C'est précisément cette prétention des élites que Wang Shivei attaqua. Voir Merle Goldman, China's Intellectuals, Cambridge, Harvard University Press, 1981.

51. le terme utilisé ici est employé dans un sens diffèrent de celui que lui donne Pierre Bourdieu. Nous nous intéressons moins aux attributs non économiques de l'échange qu'à la manière par laquelle les pratiques symboliques se développent, évoluent, se renforcent, saturent les événements et leurs imposent une signification, un sens spécial. Voir Pierre Bourdieu, Esquisse d'une théorie de la pratique, Genève, Droz, 1972. 52. L'origine de ce discours peut être retracée de plusieurs manières et parfois avec une certaine gêne placée dans la catégorie de recherche post-structuraliste associée à des figures comme Kojève, Hyppolite, Bachelard, Canguilhem, Foucault, Barthes, ou même à des post-modernistes comme Jameson, Foucault, et Baudrillard. D'autres noms peuvent être associés à la théorie du discours, par exemple Wittgenstein et Austin, même Bakhtine. Voir Paul A. Bove, "Discourse" in Frank Lentriccia and Thomas McLaughtin, (eds.) Critical Terms for Literary Study, Chicago, The University of Chicago Press, 1990.

53. Questionné à propos de l'égalité virtuelle tous les intellectuels insistèrent sur le fait que les conditions de vie étaient les mêmes pour tout le monde, les grades abolis, et qu'il y avait un fond commun entre les paysans, les soldats, les ouvriers, et les intellectuels. Mais un vieux soldat médaillé, combattant de la huitième armée de terre, qui était d'origine paysanne pauvre dit en reniflant : "Egalité ? Quelle égalité ? Ces femmes intellectuelles n'auraient jamais couché avec nous."

54. Voir Frederic Jameson, "On Magic Realism in Film", Critical Inquiry, no. 12, winter 1986, pp 301-325. On doit cependant se souvenir que comme Mao lui-même, le discours de Mao fut d'abord une théorie critique, utilisant un langage de remplacement, l'ironie à propos du passé, usant pour le présent d'un style de discours modeste et calme, incarnant une logique pour le futur. Mais ni parodie, ni allussion moqueuse ou critique ne pouvait être faite à propos du présent ou du futur. Les intellectuels et les écrivains qui pratiquaient les jeux de mots, les calembours idéographiques étaient particulièrement suspectscar ils portaient atteinte au sérieux révolutionnaire. Ce fut comme nous le verrons l'un des crimes de Wang Shivei.

55. Voir le récit fait par Zhang Guotoa in The Rise of the Chinese Communist Party, Lawrence, Kansas, The University Press of Kansas, 1972, pp. 350-360. 
56. Ibid., p. 409.

57. Ibid., p. 427.

58. Voir Red Star Over China, op. cit., pp. 210-215.

59. La vingt-cinquième armée rouge de Xu Haidong était en fait plus petite que l'ensemble des forces sous les ordres de Liu Zhidan.

60. L'histoire dit que le messager qui était supposé apporter la lettre ordonnant l'arrestation de Liu Zhidan lui montra en disant : "Vous êtes le chef militaire aussi dois je vous remettre cette lettre". Liu regarda la lettre (c'était en fait la liste des personnes qui devaient être arrêtés) avec son au nom en tout début de liste. Il remit alors la lettre dans l'enveloppe et la donna au messager. Il dit :"Allez y, apportez là à Xu Haidong, le général du front". La lettre avait été écrite par Zhu Lizhi.

61. Voir Wang Ming, Mao's Betrayal, Moscow, Progress Publishers, 1979.

62. McLane, op. cit., p. 61.

63. Voir Stuart R. Schram, The Political Thought of Mao Tsetung, New York, Praeger Publishers, 1974, p. 5

64. McLane, op. cit., pp. 74-78.

65. Il avait était réélu en 1956 au Comité Central, mais insulte finale, à la 97è position sur la liste des 97 personnes siègeant au Comité. Voir Snow, op. cit., p. 577.

66. Voir par exemple Merle Goldman, China's Intellectuals, Cambridge, Harvard University Press, 1981, p. 21. Voir aussi, Timothy Cheek, "The Fading of Wild Lilies, Wang Shiwei and Mao Zedong's Yan'an Talks in the First CPC Rectification Movement" in Australian Journal of Chinese Affairs, January, 1984, No. 11, pp. 25-57 ; et Kyna Rubin, "Writers' Discontent and Party Response in Yan'an Before 'Wild Lily', The Manchurian Writers and Zhou Yang" in Modern Chinese Literature, Vol. 1, No. 1., Sept 1984, pp 79-102. Voir aussi Guilhem Fabre, Genèse de pouvoir et de l'opposition en Chine Populaire, le Printemps de Yan'an, Paris, L'Harmattan, 1990.

67. Voir Cheek, op. cit., p. 34.

68. Je dois énormément à Wen Jize et Dai Qing pour les entretiens et les matériaux documentaires sur l'affaire Wang Shivei.

69. Comme le dit Snows dans son dernier ouvrage, "Mao n'a pas créé ou commandé les forces de l'impérialisme japonais, mais la compréhension de ces forces lui ont permis de s'emparer du commandement et des énergies du nationalisme et de la résistance patriotique pour remporter une victoire capitale pour la révolution sociale. Voir Red China Today, New York, Vintage Books, 1971, p. 69.

70. Voir à ce propos la discussion sur le contexte de la révolution puritaine en Angleterre de Christopher Hill, The World Turned Upside Down, London, Penguin Books, 1972, pp. 295-297.

71. Ainsi écrit Christopher Hill au sujet des sectes radicales de la première phase de la guerre civile anglaise, ibid., p. 272. Ces propos pourraient également s'appliquer à Robespierre, et plus même aux sans culottes qui devinrent babouvistes, Dartheans et d'autres partisans du Comité de salut public. Voir Francois Furet et Mona Ozouf, A Critical Dictionary of the French Revolution, Cambridge, Harvard University Press, 1989.

72. Voir Tang Tsou, The Cultural Revolution and Post-Mao Reforms, Chicago, University of Chicago Press, 1986. Voir également Roderick MacFarquhar, The Origins of the Cultural Revolution, Oxford, Oxford University Press, 1974, 3 Volumes.

73. Le système politique qui confondrait l'hégémonie de son propre discours avec l'efficacité de sa pratique serait tôt ou tard confronté à l'obligation d'utiliser un 
pouvoir d'Etat rigoureux, et rien ne peut dissiper plus rapidement le capital symbolique.

74. Tout comme la momie de Mao qui a un aspect de cire, plus une effigie qu'un cadavre, le portrait montre un Mao affable, sans caractère, quelque chose comme un panneau d'affichage, et même une caricature. Il lui manque un bulle peint sortant de sa bouche, dépassant au delà du mur rose avec une des citations provenant des écrits sacrés comme :"le pouvoir sort du canon du fusil". Mais comme qu'il n'y a pas de bulle on peut attribuer au président Mao toutes les pensées qu'on veut.

75. Pour un excellent exemple de phénoménologie historique voir Jacques Lafaye, Quetzalcoatl and Guadalupe,Chicago, University of Chicago Press, 1976.

76. Voir David E. Apter et Tony Saich, Revolutionary Discourse in "Mao's Republic", Cambridge, Harvard University Press, 1994.

INDEX

Mots-clés : disparitions, répression

Index géographique : Chine

Index chronologique : 1989 